\title{
A Theory of Slow-Moving Capital and Contagion $^{1}$
}

\author{
Viral V. Acharya ${ }^{2}$ \\ Hyun Song Shin ${ }^{3}$ \\ London Business School, NYU-Stern and CEPR Princeton University \\ Tanju Yorulmazer ${ }^{4}$ \\ Federal Reserve Bank of New York
}

J.E.L. Classification: G21, G28, G38, E58, D62.

Keywords: arbitrage, illiquidity, crises, contagion, spillover.

This Draft: January 2009

\footnotetext{
${ }^{1}$ The views expressed here are those of the authors and do not necessarily represent the views of the Federal Reserve System or the Federal Reserve Bank of New York.

${ }^{2}$ Contact: Department of Finance, Stern School of Business, New York University, 44 West 4th Street, Room 9-84, New York, NY-10012, US. Tel: +1 212998 0354, Fax: +1 212995 4256, e-mail: vacharya@stern.nyu.edu. Acharya is also a Research Affiliate of the Centre for Economic Policy Research (CEPR).

${ }^{3}$ Contact: Princeton University, Bendheim Center for Finance, 26 Prospect Avenue, Princeton, NJ 08540-5296, US. Tel: +1 609258 4467, Fax: +1 609258 0771, E-mail: hsshin@princeton.edu.

${ }^{4}$ Contact: Federal Reserve Bank of New York, 33 Liberty Street, New York, NY 10045, US. Tel: +1 212720 6887, Fax: +1 212720 8363, E.mail: Tanju.Yorulmazer@ny.frb.org.
} 


\title{
A Theory of Slow-Moving Capital and Contagion
}

\begin{abstract}
Fire sales that occur during crises beg the question of why sufficient outside capital does not move in quickly to take advantage of fire sales, or in other words, why outside capital is so "slow-moving". We propose an answer to this puzzle in the context of an equilibrium model of capital allocation. Keeping capital in liquid form in anticipation of possible fire sales entails costs in terms of foregone profitable investments. Set against this, those same profitable investments are rendered illiquid in future due to agency problems embedded with expertise. We show that a robust consequence of this trade-off between making investments today and waiting for arbitrage opportunities in future is the combination of occasional fire sales and limited stand-by capital that moves in only if fire-sale discounts are sufficiently deep. An extension of our model to several types of investments gives rise to a novel channel for contagion where sufficiently adverse shocks to one type can induce fire sales in other types that are fundamentally unrelated, provided arbitrage activity in these investments is sourced from a common pool of capital.
\end{abstract}

J.E.L. Classification: G21, G28, G38, E58, D62.

Keywords: fire sales, arbitrage, illiquidity, crises, spillover. 


\section{Introduction}

Our understanding of financial crises has been enhanced by a large and rapidly growing empirical literature that has documented the incidence and severity of fire sales by distressed parties in a wide range of asset classes. ${ }^{1}$ Indeed, it would not be too much of an exaggeration to say that fire sales have been a defining feature of most financial crises.

The term "fire sale" carries the connotation that assets are being sold at prices that are below some benchmark, fair fundamental price that would prevail in the absence of a crisis. However, the notion that assets are being sold at prices below their fundamental value begs an important question. How can fire sales take place in a world where arbitrage capital waits on the sidelines waiting to take advantage of artificially low prices? If there were such arbitrageurs who wait on the sidelines, would they not compete with each other as soon as the crisis erupts, providing a cushion for prices? In short, the question is how fire sales can happen as an equilibrium phenomenon when investors can choose ex ante to hold arbitrage capital in anticipation of fire-sale opportunities.

Our paper provides a theoretical framework to answer this question, and then derives implications for the social value of arbitrage capital. We show why the joint occurrence of fire sales and limited arbitrage capital is a robust equilibrium outcome arising from the following fundamental trade-off faced by investors when deciding ex ante on the allocation of capital. On the one hand, profitable activities require investments in expertise, but these very investments render them illiquid in the future due to the separation of owners who have expertise from those who finance them. On the other hand, setting aside capital in the form of liquid assets to exploit arbitrage opportunities in the future entails current costs in the form of foregone profitable investments and not investing in expertise.

In equilibrium, the two choices - whether to invest in profitable activities or to set aside funds for arbitrage in the future - must earn the same rate of return when viewed ex ante. This requirement implies that equilibrium is characterized by limited provision of arbitrage capital in the economy - where the limit is both in quantity and in expertise. Arbitrage capital being "limited" in this respect, fire sales during crises become a robust phenomenon, even though investors can anticipate them as part of the equilibrium.

Our model features an interior equilibrium where the proportion of arbitrageurs in the economy is bounded strictly away both from zero and from one. This is because if all investors

\footnotetext{
${ }^{1}$ Fire sales have been shown to exist in distressed sales of aircrafts by Pulvino (1998), in cash auctions in bankruptcies by Stromberg (2000), in creditor recoveries during industry-wide distress especially for industries with high asset-specificity by Acharya, Bharath and Srinivasan (2007), in equity markets when mutual funds engage in sales of similar stocks by Coval and Stafford (2007), and in an international setting where foreign direct investment increases during emerging market crises to acquire assets at steep discounts in the evidence by Krugman (1998), Aguiar and Gopinath (2005), and Acharya, Shin and Yorulmazer (2007).
} 
choose to undertake profitable investments, then shocks lead to steep price discounts, as there is no arbitrage capital to cushion the shock. In such a world, the shadow value of arbitrage capital is very high, and can be foreseen to be high ex ante. Some investors will therefore choose to become arbitrageurs at the ex ante stage. However, the shadow value of arbitrage capital falls as more investors choose to become arbitrageurs. If there is abundant arbitrage capital, the returns are too low to justify holding it in anticipation of crises.

In equilibrium, there is a limited amount of arbitrage capital in the economy in some states of the world at which arbitrageurs profit from fire sales. While asymmetric information when assets are complex in nature can result in fire sales, in our model the main reason for the existence of fire sales is the limited provision of arbitrage capital, whereby even non-complex assets suffer from fire-sale discounts.

The "slow-moving" nature of arbitrage capital arises from the fact that there are "learningby-doing" effects, so that arbitrageurs, being outsiders, have not invested in expertise or simply cannot do so right at the time arbitrage opportunities become available. Hence, they do not move in to acquire assets unless discounts are sufficiently steep, or in richer models, until they have gained expertise by first deploying only a part of their capital to acquire and operate some of the assets with depressed prices.

We analyze the effect of the business cycle on agents' choice to become insiders or arbitrageurs. During boom periods, risky projects are likely to perform well and there are fewer fire sale opportunities anticipated by arbitrageurs. Hence, during the upturn of the business cycle, a higher fraction of agents choose to become insiders and there is less liquid capital put aside for arbitrage. As a result, when adverse shocks hit insiders during boom periods, fire-sale effects in asset prices are more severe. This result explains why crises that erupt after a long boom are associated with sharper, more severe downturns. ${ }^{2}$ Also, as the difference between the expertise levels of insiders and arbitrageurs widens (i.e. as insiders' assets become more specific) the return arbitrageurs make from these assets decreases. In turn, arbitrageurs find it profitable to enter the market only when prices fall deeply. This reinforces fire-sale discounts further.

We put to use our equilibrium characterization of capital allocation in several extensions. We draw out the welfare implications of arbitrage, and show that (perhaps surprisingly) arbitrage capital can be detrimental for welfare. Although arbitrage capital cushions financial

\footnotetext{
${ }^{2}$ Conversely, as economic times worsen, more capital is set aside for arbitrage. For instance, according to the article titled "Cashing in on the crash" in the Economist on August 23, 2007, vulture funds raised $\$ 15.1$ billion in the first seven months of 2007 , more than the $\$ 13.9$ in all of 2006 , to take advantage of fire sales due to expected distress in financial markets. The same article points out that while some hedge funds suffered, the others, such as Citadel, Ellington, and Marathon Asset Management had the ready cash. The article highlights the strategy of Citadel to keep more than a third of its assets in cash or liquid securities, allowing it to take advantage of fire sales when opportunities arise.
} 
distress in crisis states, it can lead to inefficient levels of ex-ante investment in profitable activities. The picture that emerges from our analysis is that private incentives lead to the over-provision of arbitrage capital relative to the first best. This over-provision is in fact a manifestation of the illiquidity of profitable activities due to the underlying moral hazard problem that prevents pledging of all rents from expertise to external financiers.

We also relax two important assumptions of our benchmark model. The first is that profitable investments are completely illiquid so that arbitrage capital set aside is not used to finance surviving insiders when fire sales are undertaken by distressed insiders. The second is that insiders gain expertise relative to arbitrageurs due to learning-by-doing effects.

We show that our result holds when profitable activities have external financing capacity. We examine the ex post equilibrium between employing arbitrage capital for asset acquisition and providing finance to surviving insiders. Since arbitrageurs can make profits by acquiring assets, they must earn the same rate of return on finance provided to insiders. Hence, arbitrage capital gets allocated such that these returns are equalized. The result is that fire-sale discount in prices for acquisition of assets must equal that for provision of external finance, giving rise to a spillover or contagion from illiquidity in the market for real assets to that for financing of these assets.

In general, such contagion arises also across real and financial sectors whenever the provision of arbitrage capital in these markets is from a common pool; returns on different investments in the portfolio of an arbitrageur must be the same. The fact that the quantity of arbitrage capital is limited implies that these returns are positive in all markets where arbitrageurs allocate capital. ${ }^{3}$

In sum, we present a novel channel of contagion in which even though the fundamentals of two sectors are independent, the existence of fire sales in one sector can give rise to fire sales in the other. An alternative way of stating our result is that there is excess co-movement across sectors during crises and such co-movement is induced by limited liquidity in the market relative to the quantity of assets being put up for sale.

Finally, we relax the assumption that arbitrageurs are the ones with limited expertise. To this end, we assume that expertise is a natural endowment rather than a learning-by-doing effect, and consider two variants of our model. In the first, insiders are experts relative to arbitrageurs as in our benchmark model; in the second, agents with limited expertise become insiders so that it is arbitrageurs who have relative expertise in running assets relative to

\footnotetext{
${ }^{3}$ For (apparent) "dislocations" between different capital markets and the effect of liquidations in one market on prices in another, see an excellent discussion of the large body of extant empirical evidence in Duffie and Struvolici (2008). For similar evidence in an international setting, see Rigobon (2002) and Kaminsky and Schmukler (2007), and the discussion in Pavlova and Rigobon (2007). The literature by and large attributes such dislocations to investment-style restrictions or limited arbitrage capital.
} 
insiders. We show that the equilibrium return earned by insiders and arbitrageurs is higher in the economy where insiders are experts relative to arbitrageurs. Put another way, agents with expertise endogenously arise as insiders and the rest sit on the fence waiting for arbitrage opportunities. This lends support to our maintained assumption in rest of the paper.

\section{Related literature}

Fire sales are, of course, not new to our paper. The idea that asset prices may contain liquidity discounts when potential buyers are financially constrained and assets are not easily redeployable were discussed by Williamson (1988) and Shleifer and Vishny (1992). This early literature suggests that firms, whose assets tend to be specific (that is, whose assets cannot be readily redeployed by firms outside of the industry) are likely to experience lower liquidation values because they may suffer from fire-sale discounts in cash auctions for asset sales, especially when firms within an industry get simultaneously into financial or economic distress. Since then, fire sales have often figured in models of crises (Allen and Gale, 1994, 1998, among others). Intimately tied to the notion of fire sales is the idea that arbitrageurs wanting to buy assets at steep discounts may also face financing frictions due to principalagent problems. The resulting "limits of arbitrage" (Shleifer and Vishny, 1997) can entrench fire-sale prices for a period of time once they materialize. ${ }^{4}$

Our contribution relative to this earlier literature is to focus on the ex ante decisions of investors, which much of the literature takes as given, and thereby to explain the origins of the limited nature of arbitrage capital as an equilibrium phenomenon. In this sense, our work is closest to the analysis by Allen and Gale (2004) of the portfolio choice of banks between holding safe versus risky assets. Gorton and Huang (2004), another closely related paper, also considers the equilibrium portfolio choice of firms, deriving that it is socially inefficient to hold large quantities of safe assets required to avoid fire sales, and studying in this context the role of government bailouts during crises.

Our framework is tractable and facilitates crisp conclusions on key comparative statics and welfare questions. In particular, our result that arbitrage capital is endogenously lower in good times, and therefore, that crises arising in good times feature deeper fire-sale discounts, is a noteworthy result, which (to our knowledge) has not been discussed so far in the literature. The depth of the current global financial crisis and the long period of tranquility that preceded it provides timely motivation for our result. Another advantage of our tractable framework is to open up for scrutiny the arbitrageurs' access to different real and financial markets, and thereby identify a channel of contagion that relies purely on the limited nature of arbitrage

\footnotetext{
${ }^{4}$ Mitchell, Pedersen and Pulvino (2007) provide compelling episodic evidence for the fact that capital appears to be "slow moving" when it enters markets affected by fire-sale discounts in prices.
} 
capital.

Rampini and Viswanathan (2007) provide a dynamic contracting set-up where several features of financing by firms are endogenously derived. Their focus is on exploring which firms make investments and which preserve debt capacities for the future. This question is related to our final robustness check and their conclusion is similar; more productive firms undertake investments today rather than saving for opportunities in future. While we model fire sales as an outcome from market clearing when buyers are financially constrained, Rampini and Viswanathan model asset prices as being temporarily low due to low cash flow realizations. ${ }^{5}$

To our knowledge, our paper is the first to provide a model of contagion that owes to limited arbitrage capital. Our results on this front are closest to Gromb and Vayanos (2007) and Duffie and Struvolici (2008). Gromb and Vayanos (2007) consider arbitrageurs exploiting fire-sale opportunities across markets and this equilibrates returns they can earn in different markets. However, the quantity of equilibrium arbitrage capital is exogenous in their setting. Here, our central theoretical concern is to endogenize the quantity of arbitrage capital and illustrate that its limited quantity as well as its limited expertise make fire sales a robust equilibrium phenomenon.

In a dynamic setting Duffie and Struvolici (2008) model the "slow-moving" nature of arbitrage capital where arbitrageurs incur deadweight costs in obtaining external finance. Arbitrage capital moves in a fashion that attempts to equilibrate returns across markets, but is constrained in so doing by the financing friction. In contrast, we do not model intermediaries but instead show that the total amount of capital set aside in the economy for arbitrage activities would be limited in equilibrium. While Duffie and Struvolici (2008) take the financing friction of arbitrageurs as given, we model the friction faced by surviving industry insiders as the inherent illiquidity of their expertise, and the friction faced by outsiders as their lack of expertise relative to insiders, both justified by learning-by-doing effects. ${ }^{6}$

Bolton et al. (2008) build a model where the primary friction is asymmetric information about asset values. For liquidity needs, financial intermediaries can rely on the liquid assets in their portfolio (inside liquidity) or can sell assets (outside liquidity). The intermediary can delay the sale of its assets hoping that the crisis is temporary. However, the longer the intermediary waits, the more severe is the lemons problem and the greater is the risk to sell assets at fire-sale prices. The authors show that an immediate-trading equilibrium where intermediaries rely on inside liquidity and where prices are close to fundamental values always

\footnotetext{
${ }^{5}$ In the strict sense of the word "fire sales", as is employed in the literature following Shleifer and Vishny (1992), depressed prices due to fluctuations in fundamentals are not fire sales or arbitrage opportunities.

${ }^{6}$ Note that contagion has been derived in many other settings through portfolio flows (Kodres and Pritsker, 2002) or utility-based assumptions (Kyle and Xiong, 2001). Our model of spillover between real and financial markets is driven by limited arbitrage capital, which, in turn, is a manifestation of agency problems that limit the external financing capacity of firms.
} 
exists. However, for some parameter values, an efficient delayed trading equilibrium results, wherein intermediaries rely on outside liquidity resulting in fire-sale prices. While asymmetric information and complexity of assets is the main friction in their paper, this is not necessary in our paper: Since there is only limited provision of arbitrage capital, even non-complex assets can suffer from fire-sale discounts if shocks to insiders are sufficiently severe.

\section{Model}

The timeline for our model is given in Figure 1. There are two dates, indexed by $t \in\{0,1\}$. There is measure of 1 of risk-neutral agents who maximize their sum of profits over the two dates. Agents receive a unit endowment at date 0 and nothing else at other dates.

Each agent has access to a storage technology and a risky investment technology. The storage technology transfers each unit invested at date 0 to one unit at date 1 . One unit of investment is needed for the risky technology. The return to agent $i$ 's risky investment at date 1 is denoted by $\widetilde{R}_{i}$, where

$$
\widetilde{R}_{i}= \begin{cases}R & \text { with prob } \alpha \\ 0 & \text { with prob } 1-\alpha\end{cases}
$$

The returns $\left\{\widetilde{R}_{i}\right\}$ are independent across agents, so that by law of large numbers, precisely a proportion $\alpha$ of agents that invested in the risky technology have the high return. However, there is aggregate uncertainty in that $\alpha$ is itself random. Hence, there is uncertainty over the proportion of agents that succeed in their risky investment.

At $t=0$, agents decide whether to invest in the risky technology (and become insiders) or invest in the storage technology to become arbitrageurs. We denote the proportion of agents that become arbitrageurs by $w$. If the return is low, then the insider's entire capital is wiped out and the project is put up for sale. ${ }^{7}$ The failed insiders' assets are sold through a competitive auction at market-clearing prices. The arbitrageurs and the insiders with the high return, using their first-period return, purchase failed insiders' assets.

Crucially, we assume that arbitrageurs cannot generate the full return from insiders' assets due to their limited expertise in operating the insiders' assets. We denote the net present value of failed insiders' assets by $\bar{p}$ when they are in the hands of insiders and $\underline{p}=(\bar{p}-\Delta)$,

\footnotetext{
${ }^{7}$ Here, we do not model the bankruptcy of insiders. One can assume some fixed costs for staying in business such as rent for office space, labor costs, etc. An insider who cannot cover these costs is put up for sale. Alternatively, we can assume that when the return an insider can generate falls below a threshold value, she prefers to liquidate her business and pursue alternative forms of employment. Let $\bar{u}$ be the reservation utility of an insider to stay in business. For $u(\bar{p})<\bar{u}$, where $u$ represents the utility function of an insider, a failed insider prefers to liquidate its business.
} 
with $\Delta>0$, when they are in the hands of the arbitrageurs. We assume that $R>\bar{p}$. The notion that arbitrageurs may not be able to use insiders' assets as efficiently as existing insiders is akin to the notion of asset-specificity, first introduced in the corporate-finance literature by Williamson (1988) and Shleifer and Vishny (1992). ${ }^{8}$

Depending on the first period returns, some of the insiders (say a proportion of $k$ ) fail. Since insiders are identical at $t=0$, we denote the possible states at $t=1$ with $k$, where $k=1-\alpha$.

\section{Analysis}

We solve the model backward, by first considering the sale of failed insiders' assets and the resulting asset prices.

\subsection{Sales and liquidation values}

We keep track of two key features in the purchase of failed insiders' assets. First, surviving insiders and arbitrageurs compete with each other to acquire failed insiders' assets. Second, surviving insiders in fact may not have enough resources to acquire all failed insiders' assets. To focus on the interplay between these two features, we model the sale and liquidation stage as follows.

(i) All failed insiders' assets are pooled and competitively auctioned to the surviving insiders and arbitrageurs as described below.

(ii) The surviving insiders and arbitrageurs submit a bid function $y_{i}(p)$ for failed investors' assets. The index $i$ belongs in $[0,(1-w)(1-k)]$ if $i$ is a surviving insider, while $i \in[1-w, 1]$ if $i$ is an arbitrageur.

(iii) We assume that insiders cannot raise additional financing. ${ }^{9}$ Hence, the resources available to each surviving insider for purchasing failed insiders' assets is the payoff $R$ from the risky investment.

(iv) The price $p$ clears the market, where assets allocated to surviving insiders and arbitrageurs add up at most to the proportion of failed firms.

$$
\int_{0}^{(1-w)(1-k)} y_{i}(p) d i+\int_{1-w}^{1} y_{i}(p) d i \leq(1-w) k .
$$

(v) Concretely, we pin down the price $p$ by focusing on the symmetric case where all

\footnotetext{
${ }^{8}$ There is strong empirical support for this idea in the corporate-finance literature. See footnote 1.

${ }^{9}$ We relax this assumption later on. See sections 5.1 and 5.3.
} 
surviving insiders submit the same schedule, that is, $y_{i}(p)=y(p)$ for all $i \in[0,(1-w)(1-k)]$, and all arbitrageurs submit identical schedules, that is, $y_{i}(p)=y_{a}(p)$ for all $i \in[1-w, 1]$.

To solve for the allocation, we first derive the demand schedule for surviving insiders. The expected profit of a surviving insider from the asset purchase is $y(p)[\bar{p}-p]$. The surviving insider wishes to maximize this profit subject to the resource constraint:

$$
y(p) \cdot p \leq R
$$

Hence, for $p<\bar{p}$, surviving insiders are willing to purchase the maximum amount of assets using their resources. Thus, the optimal demand schedule for surviving insiders is

$$
y(p)=\frac{R}{p} .
$$

For $p>\bar{p}$, the demand is $y(p)=0$, and for $p=\bar{p}, y(p)$ is infinitely elastic. In words, as long as purchasing assets is profitable, a surviving insider wishes to use up all its resources to purchase assets.

We can derive the demand schedule for arbitrageurs in a similar way. Note that, arbitrageurs value these assets at $p$.

For $p<\underline{p}$, arbitrageurs are willing to supply all their funds for the asset purchase. Thus, their demand schedule is

$$
y_{a}(p)=\frac{w}{p} .
$$

For $p>\underline{p}$, the demand is $y_{a}(p)=0$, and for $p=\underline{p}, y_{a}(p)$ is infinitely elastic.

Next, we analyze how failed insiders' assets are allocated and the price function that results.

We know that in the absence of financial constraints, the efficient outcome is to sell the assets to surviving insiders. However, surviving insiders may not be able to pay the threshold price of $p$ for all assets. If price falls further, buying these assets becomes profitable for arbitrageurs and they participate in the auction.

The price cannot be greater than $\bar{p}$ since in this case we have $y(p)=y_{a}(p)=0$. If $p \leqslant \bar{p}$, and the proportion of failed insiders is sufficiently small, surviving insiders have enough funds to pay the full price $\bar{p}$ for all assets. More specifically, for $k \leq \underline{k}$, where

$$
\underline{k}=\frac{R}{R+\bar{p}}
$$

the auction price is $p^{*}=\bar{p}$. At this price, surviving insiders are indifferent between any quantity of assets purchased. Hence, each surviving insider is allocated a share $y(\bar{p})=$ $k /(1-k)$. 
For moderate values of $k$, surviving insiders cannot pay the full price for all assets but can still pay at least the threshold value of $\underline{p}$, below which arbitrageurs have a positive demand. Formally, for $k \in(\underline{k}, \bar{k}]$, where

$$
\bar{k}=\frac{R}{R+\underline{p}},
$$

the price is set at $p^{*}=(1-k) R / k$, and again, all assets are acquired by surviving insiders. Note that, in this region, surviving insiders use all available funds and the price falls as the proportion of failures increases. This effect comes from cash-in-the-market pricing, as in Allen and Gale $(1994,1998)$, and is akin to the industry equilibrium hypothesis of Shleifer and Vishny (1992) who argue that when industry peers of a firm in distress are financially constrained, the peers may not be able to pay a price for assets of the distressed firm that equals the value of these assets to them.

For $k>\bar{k}$, surviving insiders cannot pay the threshold price of $p$ for all assets and profitable options emerge for arbitrageurs. Hence, for $k>\bar{k}$, arbitrageurs have a positive demand and are willing to supply their funds for the asset purchase. With the injection of arbitrageurs' funds, prices can be sustained at $\underline{p}$ until some critical proportion of failures $\overline{\bar{k}} \geqslant \bar{k}$. However, for $k>\overline{\bar{k}}$, even the injection of arbitrageur capital is not enough to sustain the price at $\underline{p}$.

Formally, for $k \in(\bar{k}, \overline{\bar{k}}]$, where

$$
\overline{\bar{k}}=\min \left\{1, \frac{(1-w) R+w}{(1-w)(R+\underline{p})}\right\},
$$

the price is set at $\underline{p}$. At this price, arbitrageurs are indifferent between any quantity of assets purchased. Hence, each surviving insider receives a share of $y(\underline{p})=\frac{R}{\underline{p}}$, and the rest, $y_{a}(\underline{p})=(1-w)\left(k-\frac{(1-k) R}{\underline{p}}\right)$, is allocated to the arbitrageurs.

For $k>\overline{\bar{k}}$, the price is again strictly decreasing in $k$ and is given by

$$
p^{*}(k)=\frac{(1-k) R}{k}+\frac{w}{(1-w) k},
$$

and $y\left(p^{*}\right)=\frac{R}{p^{*}}$, and $y_{a}\left(p^{*}\right)=\frac{w}{p^{*}}$.

The following Lemma gives the resulting price function, which is also illustrated in Figure 2 . 
Lemma 1 The price function is given as follows:

$$
p^{*}(k)=\left\{\begin{array}{ccc}
\bar{p} & \text { for } & k \leqslant \underline{k} \\
\frac{(1-k) R}{k} & \text { for } & k \in(\underline{k}, \bar{k}] \\
\underline{p} & \text { for } & k \in(\bar{k}, \overline{\bar{k}}] \\
\frac{(1-k) R}{k}+\frac{w}{(1-w) k} & \text { for } & k>\overline{\bar{k}}
\end{array} .\right.
$$

Note that the proportion $w$ of agents that choose to become arbitrageurs affects the price $p^{*}$ only in the fourth region where $k>\overline{\bar{k}}$, as well as the boundary $\overline{\bar{k}}$ of the fourth region itself. In particular, for higher values of $w, p^{*}$ is higher in this region. Furthermore, the region itself shifts to the left since

$$
\frac{d \overline{\bar{k}}}{d w}=\frac{1}{(1-w)^{2}(R+\underline{p})}>0 .
$$

Hence, as $w$ increases, the price $p^{*}$ (weakly) increases, that is, we have $\frac{d p^{*}}{d w} \geqslant 0$.

Note that the resulting price function is downward-sloping in the proportion of failed firms $k$ in two separate regions. In the first downward-sloping region, arbitrageurs have not yet entered the market $(k \in(\underline{k}, \bar{k}])$ and there is cash-in-the-market pricing given the limited funds of surviving insiders. In the second downward-sloping region, even the funds of arbitrageurs are not enough to sustain the price at $\underline{p}$, their highest valuation of assets.

\subsection{Ex ante choice}

Insiders' expected profit, denoted by $E\left(\pi_{i}\right)$, consists of profit from their own investments, profit from asset purchases and the amount they recover for their assets when they fail, which can be derived using the price in equation 9 . In particular, we have

$$
E\left(\pi_{i}\right)=E\left[\alpha R+\alpha \frac{R}{p}(\bar{p}-p)+(1-\alpha) p-1\right],
$$

where $E$ denotes expectation over $\alpha$. Note that the only source of profit for arbitrageurs is the asset purchase at fire-sale prices. In particular, we have

$$
E\left(\pi_{a}\right)=E\left[\frac{1}{p}(\underline{p}-p)^{+}\right],
$$

where $E\left(\pi_{a}\right)$ denotes the expected profit for arbitrageurs. In equilibrium, the two payoffs are equalized at the ex ante stage, so that

$$
E\left(\pi_{i}\right)=E\left(\pi_{a}\right)
$$


as otherwise, there is an incentive for some agents to become arbitrageurs instead or viceversa.

The following proposition formally characterizes agents' choices.

Proposition 1 In equilibrium, a proportion $w^{*} \in\left(0, \frac{\underline{p}}{1+\underline{p}}\right)$ of agents choose to become arbitrageurs, where $w^{*}$ satisfies the indifference equation in (13).

Hence, in any equilibrium, the fractions of agents who choose to become insiders and arbitrageurs are bounded away from 0. Furthermore, cash-in-the-market prices are robust to the endogenous choice of arbitrage capital. That is, there will always be states of nature where price falls not only below the fundamental value of $\bar{p}$ but also below $\underline{p}$, the value arbitrageurs attach to these assets. This is a robust feature of our model. In order for arbitrage capital to be undominated, there must be states of the world where arbitrageurs make profits. In these states prices are below the arbitrageurs' valuation of assets.

Corollary 1 In equilibrium $w^{*}<\frac{\underline{p}}{1+\underline{p}}$, so that $\overline{\bar{k}}<1$, and there are states of the world where $p^{*}<\underline{p}$.

We can also derive the following proposition that sets out the relation between the level of arbitrage capital and the business cycle proxied by the aggregate distribution of successful investments, and asset specificity.

Proposition 2 Equilibrium level of arbitrage capital $w^{*}$ satisfies two features.

(i) Suppose $f$ and $g$ are two probability densities for $\alpha$, where $g$ dominates $f$ in the sense of first-order stochastic dominance. Let $w_{f}^{*}$ and $w_{g}^{*}$ be the equilibrium level of arbitrage capital under densities $f$ and $g$, respectively. Then, $w_{f}^{*}>w_{g}^{*}$.

(ii) Let $\widehat{w}=\frac{R \underline{p} \Delta}{R \underline{p} \Delta+R \bar{p}+\underline{p}^{2}}$. For $w<\widehat{w}$, as the difference of expertise between insiders and arbitrageurs widens the equilibrium proportion of arbitrageurs decreases. That is, $\frac{d w^{*}}{d \Delta}<$ 0 .

Consider (ii) first. As the difference between the expertise levels of insiders and arbitrageurs widens (i.e., as insiders' assets become more specific), the return arbitrageurs make from these assets decreases. In turn, the region over which arbitrageurs enter the market shrinks. Thus, asset specificity reinforces fire-sale discounts in prices further.

Next, consider (i). During boom periods, it is more likely that risky projects perform well. The increased probability of the high return from the risky investment has two effects 
on agents' choice that go in the same direction. First, the expected return from being an insider increases. Also, the proportion of failed insiders decreases, which limits the firesale opportunities for arbitrageurs. Hence, during boom periods, we would expect a higher fraction of agents to become insiders and take risky projects and a smaller fraction to set aside capital for arbitrage.

Furthermore, from the price function in equation 9, we know that as the fraction of arbitrageurs $w^{*}$ decreases, we observe bigger deviations in the price of failed insiders' assets from the fundamental value of $\bar{p}$. Hence, a corollary of Proposition 2 is that when adverse shocks arise during boom periods, fire-sale effects in asset prices are more severe, resulting in lower asset prices and higher price volatility. This result is a novel contribution of our analysis and provides one explanation for why crises that follow long booms are associated with greater asset price deterioration. ${ }^{10}$

Corollary 2 Adverse shocks during boom periods measured by high values of $k$ result in bigger deviations in the price of failed insiders' assets from the fundamental value of $\bar{p}$, that is, $\left(\bar{p}-p^{*}(k)\right)$ increases.

\subsubsection{Comparative statics}

We report some numerical results illustrating comparative statics. In particular, we investigate the effect of parameters $\left(\Delta, \alpha_{\max }, R, \bar{p}\right)$ on $w^{*}$ and $E\left(\pi^{*}\right)$ (see Figures 6 and 7 , respectively). In our numerical examples, we use the parameter values $\Delta=0.035, \alpha_{\max }=0.7, R=$ $2.2, \bar{p}=2$, and assume that $\alpha$ is uniformly distributed over the interval $\left[0, \alpha_{\max }\right]$, unless we state otherwise.

Figure 6a illustrates the findings in Proposition 4.2, part (ii). Furthermore, as $\Delta$ increases, the expected profit $E\left(\pi^{*}\right)$ increases, as shown in Figure 7a.

Figure $6 \mathrm{~b}$ illustrates the relation between $w^{*}$ and the business cycle analyzed in Proposition 4.2, part (i). As $\alpha_{\max }$ increases, the proportion of insiders that fail decreases (on average) and this makes fire sales less likely and less profitable. Furthermore, as $\alpha_{\max }$ increases, the expected profit from the first period investment increases. These two effects make it less attractive to become an arbitrageur. Hence, $w^{*}$ decreases as $\alpha_{\max }$ increases. Also, these two effects increase expected profits, that is, $E\left(\pi^{*}\right)$ increases as $\alpha_{\max }$ increases, as shown in Figure $7 \mathrm{~b}$.

As $R$ increases, the expected profits from the risky investment increases. Furthermore, the liquidity within a surviving insider to acquire failed insiders' assets increases. This increases

\footnotetext{
${ }^{10}$ Acharya and Viswanathan (2007) build an alternative explanation in a model where there is greater entry of poorly-capitalized institutions when fundamentals are stronger, but in their model insiders serve as arbitrageurs and there is no arbitrage capital set aside in equilibrium.
} 
expected profits $E\left(\pi^{*}\right)$ of insiders (Figure $7 \mathrm{c}$ ) and makes it more attractive to become an insider. Thus, $w^{*}$ decreases as $R$ increases (Figure 6c).

Finally, as $\bar{p}$ increases, the scrap value of the investment in the hands of insiders (also in the hands of outsiders for constant $\Delta$ ) increases. This increases expected profits $E\left(\pi^{*}\right)$, as in Figure $7 d$. Furthermore, as the scrap value of the project increases (relative to the expected profit from the first investment as well), it becomes more attractive to become an arbitrageur, relative to becoming an insider. Hence, as $\bar{p}$ increases, the proportion of arbitrageurs $w^{*}$ increases as in Figure 6d.

\subsection{Is provision of arbitrage capital efficient?}

We now identify the socially optimal level of arbitrage capital. The social planner maximizes the expected total output generated by the economy. We can write the total output of the economy as follows:

$$
E(\Pi)=E\left[w+(1-w) \alpha(R+\bar{p})+y_{I} \bar{p}+y_{A} p\right]
$$

where $y_{I}$ and $y_{A}$ represent the units of failed insiders' assets acquired by insiders and arbitrageurs, respectively, and $y_{I}+y_{A}=(1-w) k$. Note that for $E[\alpha(R+\bar{p})]>1$, the risky investment has a higher expected return than the investment in the safe asset. Furthermore, since insiders are efficient users of assets relative to the arbitrageurs, that is, $\underline{p}<\bar{p}$, the expected total output increases as more (less) failed insiders' assets are acquired by surviving insiders (arbitrageurs). However, when $w$ is high, arbitrageurs compete with surviving insiders for failed insiders' assets. Hence, the expected total output decreases as arbitrage capital $w$ increases. We have the following proposition.

Proposition 3 For $E[\alpha(R+\bar{p})]>1$, the socially optimal proportion of agents that become arbitrageurs is 0 . That is, $w^{* *}=0$.

To summarize, when profitable investments dominate safe assets, arbitrage capital is an inefficient way of allocating resources in the economy. While richer settings with risk-averse agents and contagious effects of price meltdowns (e.g., due to marking-to-market constraints) may create some efficient role for arbitrage capital, the ex ante inefficiency arising from foregone profitable investments would arise in such settings too. In this sense, our analysis provides a counterpoint to the generally accepted wisdom that price stability arising from entry of arbitrage capital is welfare-enhancing.

From Proposition 3, we know that in our set-up, the first-best is to have no arbitrage capital. One way a regulator can achieve that outcome is to diminish the returns to arbitrage 
capital by not allowing the asset price to fall below arbitrageur's valuation $p$. The regulator can achieve this in a variety of ways. For example, the regulator can price discriminate and set the price at $p$ for arbitrageurs whereas it can charge a lower price for surviving insiders. While this can be a too extreme form of intervention, alternatively, the regulator can provide sufficient liquidity to the system ex post. This can, for example, be achieved by bailing out some of the failed agents or by providing liquidity to surviving insiders so that the price never falls below $\underline{p}$ and, in turn, agents do not hold any arbitrage capital. If liquidity injections result in fiscal costs, in general the regulator can only achieve second-best, which results in a better outcome than the competitive equilibrium. Hence, the competitive equilibrium we have is in general constrained inefficient. However, in this paper, we do not provide a detailed analysis of (constrained) (in)efficiency of the competitive outcome since our main focus is to derive more positive results from the model by relaxing some of its assumptions.

\section{Contagion}

In this section, we extend the benchmark model to analyze a novel channel for contagion from the real to the financial markets, as well as across different real and financial assets. This form of contagion results from illiquidity when arbitrage capital for different assets and markets comes from a common pool. Put differently, we characterize a form of excess co-movement of prices across different sectors resulting from scarcity of arbitrage capital and illiquidity.

For the remainder of the paper, we normalize the measure of insiders to $1 .{ }^{11}$ We continue to denote the arbitrageur funds by $w$, where $w$ is at a level such that the price for assets has the four regions as in Proposition 1.

\subsection{Contagion from real to financial markets}

In this extension we relax assumption (iii) of our benchmark model (Section 4.1) that restricts insiders' ability to raise external financing at date 1. In particular, we allow insiders to generate funds from arbitrageurs against the assets they acquire and analyze contagion from fire sales in the market for real assets to the market for financing of those assets. Even though arbitrageurs are inefficient in running insider assets, when the price is sufficiently low, arbitrageurs make profits from acquiring and running these assets. Hence, arbitrageurs ask for similar discounts to finance insiders. The result is a spillover or contagion from real assets to financial assets used for funding real assets.

Formally, we allow insiders to generate funds at $t=1$ against the assets they acquire. In

\footnotetext{
${ }^{11}$ This simplifies our expressions significantly and does not change any of our results qualitatively.
} 
particular, surviving insiders issue shares to generate funds of $q(k)$ per unit of share issued. Hence, if a surviving insider issues $s$ units of shares, the funds it has for acquiring failed insiders' assets at $t=1$ is equal to $[R+s q(k)]$.

Note that this total liquidity available with the surviving insiders for asset purchases is higher compared to the benchmark case. As a result, the region over which we observe cashin-the-market pricing is smaller, i.e., starts at a larger proportion of failures, compared to the benchmark case.

With this extension of the model, we have two markets: one for assets of failed insiders and one for shares of surviving insiders. To find the equilibrium prices and allocations in these two markets, we formally state the optimization problem that surviving insiders and arbitrageurs face.

If a surviving insider issues $s$ units of shares at the price $q(k)$ and purchases $m$ units of assets at the price $p(k)$, it makes an expected profit of $m(\bar{p}-p(k))-s(\bar{p}-q(k))$.

Note that in any equilibrium, $q(k)$ cannot exceed $\bar{p}$. Thus, we have $q(k) \leqslant \bar{p}$, and surviving insiders issue equity just enough for the asset purchase, not more. Using this, we can state a surviving insider's maximization problem as:

$$
\begin{array}{cc}
\max _{m, s} & m(\bar{p}-p(k))-s(\bar{p}-q(k)) \\
\text { s.t. } & s \cdot q(k)+R \geqslant m \cdot p(k) \\
& s \leqslant m .
\end{array}
$$

For $q(k) \leqslant p(k)$, surviving insiders cannot make positive profits by issuing equity to purchase assets. Thus, when $q(k) \leqslant p(k), s=0$ and $m=\frac{R}{p(k)}$. And when $q(k)>p(k)$, surviving insiders make positive profits from asset purchase using the funds they generate by issuing equity. Hence, they would like to issue as much equity as possible, that is, $s=m$.

We can state each arbitrageur's maximization problem in a similar way:

$$
\begin{array}{ll}
\max _{x, y} & x(\underline{p}-p(k))+z(\bar{p}-q(k)) \\
\text { s.t. } & x \cdot p(k)+z \cdot q(k) \leqslant 1
\end{array}
$$

where $x$ and $z$ represent the proportion of assets and the proportion of shares in surviving insiders purchased by arbitrageurs, respectively.

When the share price of surviving insiders, $q(k)$, is relatively low compared to the price of failed insiders' assets, $p(k)$, arbitrageurs prefer to purchase shares of surviving insiders. However, if $p(k)$ becomes low compared to $q(k)$, then arbitrageurs may prefer to acquire the assets directly. 
When $p(k)>\underline{p}$, arbitrageurs do not want to purchase assets and $x(q, p)=0$. When $p(k)<\underline{p}$, arbitrageurs choose $x$ to maximize:

$$
\begin{aligned}
& x(\underline{p}-p(k))+\left(\frac{w-x p(k)}{q(k)}\right)(\bar{p}-q(k)) \\
= & x\left(\underline{p}-\frac{p(k) \bar{p}}{q(k)}\right)+w\left(\frac{\bar{p}}{q(k)}-1\right) .
\end{aligned}
$$

Thus, if $p(k)<\underline{p}$ and $\underline{p} q(k)>\bar{p} p(k)$, then arbitrageurs use all their funds for the asset purchase, that is $x=\frac{\bar{w}}{p(k)}$. When $p(k)<\underline{p}$ and $\underline{p} q(k)<\bar{p} p(k)$, arbitrageurs use all their funds for the equity purchase, that is $y=\frac{w}{q(k)}$, and when $\underline{p} q(k)=\bar{p} p(k)$, arbitrageurs are indifferent between the equity and the asset purchase.

In equilibrium, demand for shares of surviving insiders and assets of failed insiders should equal their supply. Hence, we have the market clearing conditions:

$$
\begin{array}{lc}
(1-k) s=z & \text { (equity market) } \\
(1-k) m+x=k & \text { (asset market) }
\end{array}
$$

We concentrate on the equilibrium where the participation of arbitrageurs in the equity market is maximum, which results in the maximum price for assets. However, even in this setup, we show that for a large proportion of failures, the share price of surviving insiders falls below their fundamental value $\bar{p}$.

The equilibrium price functions for failed insiders' assets and for shares of surviving insiders are formally stated in the following proposition and illustrated in Figure 3.

Proposition 4 In equilibrium, the prices for real assets and financial shares are respectively:

$$
p^{*}(k)=\left\{\begin{array}{ccc}
\bar{p} & \text { for } \quad k \leqslant \widehat{k} \\
\frac{(1-k) R+w}{k} & \text { for } \quad \widehat{k}<k
\end{array}\right.
$$

and

$$
q^{*}(k)=\left\{\begin{array}{ccc}
\bar{p} & \text { for } & k \leqslant \overline{\bar{k}} \\
\mu p^{*}(k) & \text { for } & k>\overline{\bar{k}}
\end{array},\right.
$$

where $\mu=\frac{\bar{p}}{\underline{p}}, \widehat{k}=\frac{R+w}{R+\bar{p}}$, and $\overline{\bar{k}}=\frac{R+w}{R+\underline{p}}$.

As Proposition 4 shows, the price of shares of surviving insiders follows an interesting pattern. When the proportion of failures is large, cash-in-the-market pricing results in the 
price of assets falling below the threshold value of arbitrageurs, $p$. Since purchasing assets at such prices becomes profitable for arbitrageurs, in equilibrium they need to be compensated for purchasing shares of surviving insiders. As a result, share price of surviving insiders falls below their fundamental value, $\bar{p}$. In other words, surviving insiders can raise equity financing only at discounts. Thus, limited funds within the whole system and the resulting cash-in-themarket pricing affects not only the price of real assets but also the price of shares of surviving insiders. Furthermore, the discount that surviving insiders need to suffer in issuing equity is higher when the crisis is more severe (high $k$ ).

One important observation is that the introduction of capital markets do not affect arbitrageurs' expected profit. The reason for this is that even though arbitrageurs can acquire shares of surviving insiders, in equilibrium, arbitrageurs make the same profit from asset and share purchases. Hence, more generally, for the same level of arbitrageur capital $w, E\left(\pi_{a}\right)$ is the same as in the case with no capital markets.

However, insider profits, $E\left(\pi_{i}\right)$, are not necessarily the same. With the introduction of capital markets, on the one hand, prices are (weakly) higher but on the other hand, insiders can acquire more assets as they have more funds. Even though the resulting overall effect on insiders' expected profits is ambiguous, our results do not change qualitatively as in equilibrium arbitrageurs need to make positive expected profits as in the earlier results from Section 4 . This requires that there be limited arbitrageur capital in equilibrium so that the price falls below $p$ in states with high proportion of failures $k$.

\subsubsection{Limited pledgeability}

So far, we assumed full pledgeability. However, due to various imperfections such as asymmetric information, moral hazard, etc., surviving insiders may not be able to fully pledge their future cash flows. Suppose there is moral hazard à la Holmstrom and Tirole (1998). If an insider does not exert effort, then she cannot generate $\bar{p}$ but only $(\bar{p}-\bar{\Delta})<\underline{p}$ and enjoys a non-pecuniary benefit of $B \in(0, \bar{\Delta})$. Thus, for insiders to exert effort, appropriate incentives have to be provided by giving them a minimum share of the future profits. We denote this share as $\theta$. We can write the incentive-compatibility constraint as follows:

$$
\theta \bar{p} \geqslant \theta(\bar{p}-\bar{\Delta})+B . \quad(I C)
$$

Using the (IC) constraint, we can show that insiders need a minimum share of $\bar{\theta}=\frac{B}{\Delta}$ to exert effort. ${ }^{12}$ Therefore, insiders can generate at most a fraction $\tau=(1-\bar{\theta})$ of its future income from the asset purchases in the capital market if it is required to exert effort. ${ }^{13} \mathrm{We}$

\footnotetext{
${ }^{12}$ See Hart and Moore (1994) for a model with similar incentive-compatibility constraints.

${ }^{13}$ Note that, once the firm is left with a share that is less than $\bar{\theta}$, it can as well pledge the entire future return of $(\bar{p}-\bar{\Delta})$. For $\bar{\Delta}>\sqrt{B \bar{p}}$, this is less than $(1-\bar{\theta}) \bar{p}$, the amount that can be pledged when the
} 
assume that at $t=0$, the entire share of the profits belongs to the insider, and therefore, moral hazard is not a concern.

Because of moral hazard at $t=1$, insiders cannot generate the full value against the value of the assets they acquire, but only $\tau q(k)$, where $q(k)$ is the price of equity share in surviving insiders, purchased by arbitrageurs. Hence, when a proportion $k$ of insiders fail, the maximum amount of funding available with the surviving insiders for the purchase of assets, including funds that can be generated against returns from purchased assets, is given as:

$$
L(k)=(1-k)[R+\tau m q(k)]
$$

where $m$ is the units of assets acquired by each surviving insider. Since, insiders cannot fully pledge the return from the assets they acquire, it is possible that all the funds $w$ with the arbitrageurs cannot go to surviving insiders through the capital market. In particular, for $\tau(1-k) m q(k)<w<(1-k) m q(k)$, only a fraction of arbitrageur capital goes to surviving insiders through the capital market, whereas some of the arbitrageur capital goes directly to the asset market, leading to a misallocation cost.

For this case, under limited pledgeability, the price functions for failed insiders' assets and for shares of surviving insiders are given as follows (illustrated in Figure 4): ${ }^{14}$

Proposition 5 In equilibrium, prices for real assets and financial shares are respectively:

$$
p^{*}(k)=\left\{\begin{array}{ccc}
\bar{p} & \text { for } & k \leqslant \widetilde{k} \\
\frac{(1-k) R+k \tau \bar{p}}{k} & \text { for } & \widetilde{k}<k \leqslant \widetilde{\widetilde{k}} \\
\underline{p} & \text { for } & \widetilde{\widetilde{k}}<k \leqslant \overline{\bar{k}} \\
\frac{(1-k) R+w}{k} & \text { for } & \overline{\bar{k}}<k
\end{array}\right.
$$

and

$$
q^{*}(k)=\left\{\begin{array}{ccc}
\bar{p} & \text { for } & k \leqslant \overline{\bar{k}} \\
\mu p^{*}(k) & \text { for } & k>\overline{\bar{k}}
\end{array}\right.
$$

where $\widetilde{k}=\frac{R}{R+\bar{p}(1-\tau)}<\widehat{k}$ and $\widetilde{\widetilde{k}}=\frac{R}{R+\underline{p}-\tau \bar{p}}<\overline{\bar{k}}$.

The results stated are for the case $w \geqslant \tau \bar{p}$. This is a more interesting case since, due to moral hazard, all arbitrageur capital does not go to surviving insiders through the capital

surviving insider exerts effort. Throughout, we assume that $\bar{\Delta}>\sqrt{B \bar{p}}$.

${ }^{14}$ We assume that $\tau<\underline{p} / \bar{p}$, which boils down to $\bar{\Delta}<\frac{B \bar{p}}{\Delta}$. 
market. In particular, we have $\widetilde{k}<\widehat{k}$ so that the price starts to fall below the fundamental value of $\bar{p}$ for a smaller proportion of failures. Furthermore, for $\widetilde{\widetilde{k}}<k \leqslant \overline{\bar{k}}$, the arbitrageur funds that cannot go to the capital market enter directly into the asset market. With the injection of additional arbitrageur capital, the asset price can be sustained at $\underline{p}$. However,

for $k>\overline{\bar{k}}$, all arbitrageur funds, directly or through surviving insiders, enter into the asset market so that prices are the same as in the case with full pledgeability.

\subsection{Contagion across countries}

In this extension, we introduce another country (or industry, asset) into the benchmark model. The objective is to analyze how illiquidity and the allocation of arbitrageur funds between the two countries' assets can lead to contagion from one country to the other, resulting in excessive co-movement across assets that have independent fundamentals.

Suppose that there are two ex-ante identical countries, denoted by $i \in\{1,2\}$, each with a measure 1 of insiders. For the sake of simplicity of notation, we assume that these two countries have identical features to the economy introduced in the benchmark model except that their shocks are independent. The insiders only access markets in their own country whereas arbitrageurs can access markets in both countries. Since, in this section, our focus is the spillover between the asset markets, we use the benchmark model where insiders cannot raise any funding in the capital market. In Section 5.3, we relax this assumption and investigate its implications for spillover from real to financial markets across countries.

Insiders in country $i$ are willing to pay a maximum price of $\bar{p}_{i}=\bar{p}$, whereas arbitrageurs are willing to pay a maximum price of $\underline{p}_{i}=\underline{p}$, for failed firms' assets in country $i=1,2$.

Arbitrageurs can allocate their funds of $w$ into these two countries, where $w_{i}$ represents the funds allocated to country $i=1,2$, with $w_{1}+w_{2}=w$. Suppose that a fraction $k_{i}$ of insiders in country $i$ fails at $t=1$.

For relatively small proportion of failures in the two countries, the asset prices in the two countries are above the threshold price $\underline{p}$ arbitrageurs are willing to pay and arbitrageurs do not enter the asset markets. Formally, for

$$
\sum_{i=1,2} \max \left\{0,\left(k_{i} \underline{p}-\left(1-k_{i}\right) R\right)\right\} \leqslant w
$$

total liquidity of insiders is sufficiently high, so that, there are no profitable options for arbitrageurs. However, for $k_{i}>\overline{\bar{k}}_{i}\left(k_{j}\right)$, for $i \neq j$, where

$$
\overline{\bar{k}}_{i}\left(k_{j}\right)=\frac{R+w-\max \left\{0,\left(k_{j} \underline{p}-\left(1-k_{j}\right) R\right)\right\}}{R+\underline{p}},
$$


total liquidity of insiders is not sufficient to keep the asset prices above the threshold of arbitrageurs and profitable options for arbitrageurs emerge in these two countries. Note that the threshold $\overline{\bar{k}}_{i}$ is decreasing in $k_{j}$ since $\frac{d \overline{\bar{k}}_{i}}{d k_{j}} \leqslant 0$. Hence, country $i$ enters the second cash-inthe-market region relatively sooner when country $j$ experiences a more severe crisis (higher $k_{j}$ ). In this case, in equilibrium, arbitrageurs allocate their funds in these two countries such that they make the same profit from asset purchases in the two countries, which implies that in equilibrium,

$$
\frac{\underline{p}-p_{i}}{p_{i}}=\frac{\underline{p}-p_{j}}{p_{j}}, \text { that is, } p_{i}=p_{j} .
$$

We obtain the following proposition that formalizes the contagion effects on asset price in country $i$ from country $j$ (also illustrated in Figure 5). The proposition also shows the level of arbitrageur capital that is channelled to each country, and its determinants such as the severity of crisis in these countries.

Proposition 6 Suppose that arbitrageurs can access two countries $i=1,2$, where they allocate $w_{i}$ of their funds in country $i$ with $w_{1}+w_{2}=w$. Let $k_{i}$ be the proportion of insiders that fail in country $i$ at $t=1$. The price of assets as a function of the proportion of failed insiders in both countries ( $i$ and $j, i \neq j$ ) is as follows:

$$
p_{i}^{*}\left(k_{i}, k_{j}\right)=\left\{\begin{array}{ccc}
\bar{p} & \text { for } & k_{i} \leqslant \underline{k} \\
\frac{\left(1-k_{i}\right) R}{k_{i}} & \text { for } & k_{i} \in(\underline{k}, \bar{k}] \\
\underline{p} & \text { for } & k_{i} \in\left(\bar{k}, \overline{\bar{k}}_{i}\left(k_{j}\right)\right] \\
\frac{\left(1-k_{i}\right) R+w_{i}^{*}}{k_{i}} & \text { for } & k_{i}>\overline{\bar{k}}_{i}\left(k_{j}\right)
\end{array}\right.
$$

where $\overline{\bar{k}}_{i}\left(k_{j}\right)$ is given as in equation (28), and

$$
w_{i}^{*}=\frac{k_{i}(R+w)-k_{j} R}{k_{i}+k_{j}} .
$$

Furthermore, we have $\frac{d w_{i}^{*}}{d k_{i}} \geqslant 0$ and $\frac{d w_{i}^{*}}{d k_{j}} \leqslant 0$.

The limited liquidity leads to cash-in-the-market prices for assets in domestic markets, which creates profitable options for arbitrageurs. To take advantage of these options, arbitrageurs channel their resources towards countries where assets are sold at fire-sale prices. However, when arbitrageur funds are limited, this would result in a flight of arbitrageur capital from other countries since, in equilibrium, arbitrageurs need to be making the same level of profit in different countries. Hence, fire-sale discounts in one country can have spillover 
or contagion effect on other countries that are not hit by the same shock and in that sense are fundamentally unrelated. This is due to limited liquidity of surviving insiders of a country, limited quantity of liquid arbitrage capital, and arbitrageurs' ex-post portfolio allocation decision.

\subsection{Spillover across assets and across real and financial sectors}

We can also allow for arbitrageurs to provide financial capital to surviving insiders, in addition to the asset markets, in both countries. Hence, the analysis in this section generalizes the analysis in sections 5.1 and 5.2. In equilibrium, arbitrageurs need to make the same profit from acquiring shares or assets in the two countries, and this should hold even if capital markets in one or both countries shut down completely.

For relatively small proportion of failures in the two countries, the asset prices in the two countries are above the threshold price $\underline{p}$ arbitrageurs are willing to pay and arbitrageurs do not enter the asset markets. Formally, when condition in inequality (27) is satisfied, there are no profitable options for arbitrageurs. However, for $k_{i}>\overline{\bar{k}}_{i}\left(k_{j}\right)$, where $\overline{\bar{k}}_{i}\left(k_{j}\right)$ is given in equation (28), total liquidity is low enough so that profitable options for arbitrageurs emerge in these two countries. In that case, in equilibrium, arbitrageurs allocate their funds in these two countries such that they make the same profit from real assets and share purchases in the two countries. This implies that in equilibrium:

(1) $p_{i}=p_{j}$

(2) $q_{i}=\mu p_{i}$, for $i=1,2$, where $\mu=\frac{\bar{p}}{\underline{p}}$.

Note that these conditions give us the result that illiquidity may lead to contagion across real and financial sectors, both within a country as well as across countries. In particular, when a large proportion of insiders fail in country $i$, by equilibrium condition (1) above, this may have an effect on asset prices in country $j$. Furthermore, the fire-sale discount in the asset market of country $i$ also affects the financial markets in both countries through equilibrium condition (2) above. ${ }^{15}$

\section{Robustness}

In the analysis so far, insiders are more efficient in running assets. This is because of the expertise insiders gain through learning-by-doing, that is, expertise is acquired. In this sec-

\footnotetext{
${ }^{15} \mathrm{~A}$ complete derivation of the asset and share prices in both countries would be a repeat of the analysis in sections 5.1 and 5.2. For the purpose of brevity, it is omitted from the current paper.
} 
tion, we allow for "experts" and "non-experts" in the model, where expertise or lack thereof is an endowment to start with. In particular, experts can generate the high return $R$, while non-experts can only generate $(R-\widehat{\Delta})$ from the risky investment when the return is high. Furthermore, experts value failed insiders' assets at $\bar{p}$ whereas non-experts are willing to pay a maximum price of $\underline{p}=\bar{p}-\Delta$ for these assets. To keep the expertise levels consistent and comparable with the earlier set-up, we make the additional assumption that $\Delta=E(\alpha) \widehat{\Delta}$.

We analyze which set of agents choose to become insiders as opposed to arbitrageurs. We discuss two different cases. In the first case (Model I), experts become insiders, whereas in the second case (Model II) experts stay as arbitrageurs. The formal analysis of these two cases can be found in Appendix II.

Model I is very similar to the case we analyzed so far.

In Model II, non-experts become insiders and experts stay as arbitrageurs. In this case, arbitrageurs value failed insiders' assets at $\bar{p}$ whereas surviving insiders are willing to pay a maximum price of $\underline{p}$ for these assets. Also, note that the resources available with each surviving insider for purchasing and running the failed insiders' assets, denoted by $\widehat{R}$, equal $\widehat{R}=R-\widehat{\Delta}$.

Hence, for small proportion of failures, failed insiders' assets are purchased by arbitrageurs. Surviving insiders start purchasing assets only when the price falls below $\underline{p}$. Again, we have the four-region price function as in equation (9). However, for low and moderate proportion of failures, arbitrageurs purchase all failed insiders' assets and insiders start purchasing assets only when price falls to $\underline{p}$, that is, when proportion of failures is high. And, for very high proportion of failures, we have the fourth region where price falls below $\underline{p}$.

Below, we provide some numerical results for a comparative statics analysis. In the numerical examples, we use the same values as in the benchmark model, that is, $\widehat{\Delta}=.1, \alpha_{\max }=$ $.7, R=2.2, \bar{p}=2$, and assume that $\alpha$ is uniformly distributed over the interval $\left[0, \alpha_{\max }\right]$, unless we state otherwise.

Figures 8a and 9a illustrate, respectively, the different effects of the difference between the expertise levels of insiders and arbitrageurs $(\Delta, \widehat{\Delta})$ in Model I and Model II on $w^{*}$ and expected profits $E\left(\pi^{*}\right)$. As opposed to Model I, in Model II, as this difference widens, the price surviving insiders are willing to pay for failed insiders' assets decreases. In turn, the region over which surviving insiders enter the asset market shrinks. Due to these two effects, the expected profit of insiders decreases and the equilibrium proportion of agents that become arbitrageurs $\left(w_{2}^{*}\right)$ increases.

Figures $8 \mathrm{~b}$ and $9 \mathrm{~b}$ are analogous to Figures $6 \mathrm{~b}$ and $7 \mathrm{~b}$, respectively, that is, $w^{*}$ is decreasing in $\alpha_{\max }$ whereas $E\left(\pi^{*}\right)$ is increasing in $\alpha_{\max }$ in Model II as well. The comparative statics on $R$ give qualitatively the same results on $w^{*}$ and $E\left(\pi^{*}\right)$ in Model II as in Model I in that as $R$ 
increases, in both models, $w^{*}$ decreases and $E\left(\pi^{*}\right)$ increases (Figures $8 \mathrm{c}$ and $9 \mathrm{c}$ ).

Finally, the comparative statics on $\bar{p}$ also give qualitatively the same results on $w^{*}$ and $E\left(\pi^{*}\right)$ in Model II as in Model I. As $\bar{p}$ increases, $w^{*}$ and $E\left(\pi^{*}\right)$ increase. These results are depicted in Figures $8 \mathrm{~d}$ and $9 \mathrm{~d}$, which are analogous to Figures $6 \mathrm{~d}$ and $7 \mathrm{~d}$, respectively.

The more interesting result is that the expected profit in Model I is higher than the expected profit in Model II. This means that unless there are some frictions such as barriers to entry, experts always choose to become insiders whereas non-experts become arbitrageurs. Furthermore, the wedge between profits in the two models widens as $\widehat{\Delta}$ (and $\Delta$ ) increases. Hence, as insider assets become more specific (higher $\Delta$ and $\widehat{\Delta}$ ), the incentive of experts to become insiders is reinforced and only a larger friction (higher barriers of entry, for example) can result in non-experts becoming insiders. This provides at least a numerical justification for our benchmark assumption that arbitrageurs' expertise in running assets is lower than that of insiders.

\section{Conclusion}

Our theoretical framework sheds light on fire sales as an equilibrium phenomenon when investors can choose ex ante how much arbitrage capital to hold. The joint occurrence of fire sales and limited arbitrage capital that moves in "slowly" to acquire assets (that is, only when price discounts are sufficiently steep) is a robust feature arising from the fundamental trade-off faced by investors. Profitable activities require investments in expertise, but these very investments render them illiquid due to attendant agency problems. Arbitrage capital can take advantage of depressed prices in crisis states, but entails costs in the form of foregone profitable investments and not investing in expertise. Equalizing the ex ante return from the two activities leads to the interior nature of the equilibrium. Equilibrium arbitrage capital is limited and fire sales during crises become a robust phenomenon.

We demonstrated how our equilibrium construction can be used to good effect in two applications. First, we showed that (perhaps surprisingly) setting aside of arbitrage capital can be inefficient from the standpoint of ex-ante investment. Although arbitrage capital cushions financial distress in crisis states, it leads to foregoing of ex-ante profitable investments. Our second application of the equilibrium construction was to examine a novel channel of contagion between fundamental sectors that have independent fundamentals. The contagious link arises from the fact that arbitrageurs must earn the same rate of return on capital from different markets to which they supply liquidity.

It would be interesting in future research to examine a dynamic setting in which one can study how arbitrage capital allocation shifts over time, in particular, as crises approach, and 
calibrate the resulting prices and contagion across markets to empirically observed patterns. 


\section{References}

Acharya, Viral, Sreedhar Bharath and Anand Srinivasan. 2007. Does Industry-wide Distress Affect Defaulted Firms? - Evidence from Creditor Recoveries. Journal of Financial Economics, 85(3): 787-821.

Acharya, Viral, Hyun Song Shin and Tanju Yorulmazer. 2007. Fire-Sale FDI. Working Paper, London Business School.

Acharya, Viral and S. (Vish) Viswanathan. 2007. Leverage, Moral Hazard and Liquidity. Working Paper, London Business School.

Aguiar, Mark and Gita Gopinath. 2005. Fire-Sale FDI and Liquidity Crises. Review of Economics and Statistics, 87(3): 439-452.

Allen, Franklin, and Douglas Gale. 1994. Liquidity Preference, Market Participation and Asset Price Volatility. American Economic Review, 84: 933-955.

Allen, Franklin, and Douglas Gale. 1998. Optimal Financial Crises. Journal of Finance, 53: $1245-1284$.

Berger, Philip, Eli Ofek and Itzhak Swary. 1996. Investor Valuation of the Abandonment Option. Journal of Financial Economics, 42: 257-287.

Bolton, Patrick, Tano Santos and Jose Scheinkman. 2008. Inside and Outside Liquidity. Working Paper, Columbia University.

Coval, Joshua, and Erik Stafford. 2007. Asset Fire Sales (and Purchases) in Equity Markets. Journal of Financial Economics, 86(2): 479-512.

Duffie, Darrell and Bruno Strulovici. 2008. Capital Mobility and Asset Prices. Working Paper, Stanford University.

Gorton, Gary and Lixin Huang. 2004. Liquidity, Efficiency, and Bank Bailouts. American Economic Review, 94(3): 455-483.

Gromb, Denis and Dimitri Vayanos. 2007. Financially Constrained Arbitrage and CrossMarket Contagion. Working Paper, London Business School.

Hart, Oliver, and John Moore. 1994. A Theory of Debt Based on the Inalienability of Human Capital. Quarterly Journal of Economics, 109(4): 841-879.

Holmstrom, Bengt, and Jean Tirole. 1998. Private and Public Supply of Liquidity. Journal of Political Economy, 106(1): 1-40. 
Kaminsky, Graciela and Sergio L. Schmukler. 2002. Emerging Market Instability: Do Sovereign Ratings Affect Country Risk and Stock Returns? World Bank Economic Review, 16(2): 171-195.

Kodres, Laura and Matthew Pritsker. 2002. A Rational Expectations Model of Financial Contagion. Journal of Finance, 57(2), 769-799.

Krugman, Paul. 1998. Fire-sale FDI. Available at http://web.mit.edu/krugman/www/FIRESALE.htm.

Kyle, Albert and Wei Xiong. 2001. Contagion as a Wealth Effect. Journal of Finance, 56, 1401-1440.

Mitchell, Mark, Lasse Pedersen and Todd Pulvino. 2007. Slow Moving Capital. American Economic Review, Papers and Proceedings, 97(2): 215-220.

Pavlova, Anna and Roberto Rigobon. 2007. The Role of Portfolio Constraints in the International Propagation of Shocks. Review of Economic Studies, 75: 1215-1256.

Pulvino, Todd C. 1998. Do Asset Fire Sales Exist: An Empirical Investigation of Commercial Aircraft Sale Transactions. Journal of Finance, 53: 939-978.

Rampini, Adriano A., and S. Viswanathan. 2007. Collateral, Financial Intermediation, and the Distribution of Debt Capacity. Working Paper, Fuqua School of Business, Duke University.

Rigobon, Roberto. 2002. The Curse of Non-Investment Grade Countries. Journal of Development Economics, 69(2): 423-449.

Shleifer, Andrei, and Robert Vishny. 1992. Liquidation Values and Debt Capacity: A Market Equilibrium Approach. Journal of Finance, 47: 1343-1366.

Shleifer, Andrei and Robert W. Vishny, (1997) "The Limits of Arbitrage", Journal of Finance, 52(1), 25-55.

Stromberg, Per. 2000. Conflicts of Interest and Market Illiquidity in Bankruptcy Auctions: Theory and Tests. Journal of Finance, 55: 2641-2692.

Williamson, Oliver E. 1988. Corporate Finance and Corporate Governance. Journal of Finance, 43: 567-592. 


\section{Appendix I: Proofs}

Proof of Proposition 1: We prove the results that $w^{*} \in(0,1)$ and $k^{*}<1$ jointly by analyzing all the five possible regions for $k$ that are given in equation (9).

From the indifference equation (13), we have ${ }^{16}$

$$
E\left[\alpha\left(\frac{R \bar{p}}{p}\right)+(1-\alpha) p-1\right]=E\left[\frac{1}{p}(\underline{p}-p)^{+}\right],
$$

which can be written as

$$
E\left[\frac{1}{p}(\underline{p}-p)^{+}-\alpha\left(\frac{R \bar{p}}{p}\right)-(1-\alpha) p+1\right]=0 .
$$

From equation (33), the equilibrium level of $w^{*}$ is implicitly given as

$$
\begin{aligned}
& E\left[h\left(\alpha, w^{*}\right)\right]=0, \text { where } \\
& h(\alpha, w)=\frac{1}{p}(\underline{p}-p)^{+}-\alpha\left(\frac{R \bar{p}}{p}\right)-(1-\alpha) p+1 .
\end{aligned}
$$

Recall that we have $\alpha=(1-k)$. Hence, $h(\alpha, w)$ can also be written as

$$
h(k, w)=\frac{1}{p}(\underline{p}-p)^{+}-(1-k)\left(\frac{R \bar{p}}{p}\right)-k p+1 .
$$

Next, we show that $E[h(\alpha, w)]$ is (weakly) decreasing in $w$. Note that the price $p^{*}(k)$ given in equation (9) is continuous in $w$. Hence, $h(k, w)$ is continuous in $w$. Thus, using Leibnitz's rule, we can show that

$$
\frac{\partial E(h)}{\partial w}=\int_{k=0}^{1}\left(\frac{\partial h}{\partial w}\right) f(k) d k .
$$

Note that $w$ affects $h(k, w)$ only through the price $p$. From equation $(9)$, for $k \leqslant \overline{\bar{k}}$, price $p$ is independent of $w$, so that $\frac{\partial h}{\partial w}=0$.

For $k>\overline{\bar{k}}$, we have

$$
h\left(k, w^{*}\right)=\frac{\underline{p}-(1-k) R \bar{p}}{p}-k p,
$$

\footnotetext{
${ }^{16}$ While the price depends on $w$ and $k$, for simplicity of notation we use $p$ instead of $p(k, w)$.
} 
which gives us

$$
\frac{\partial h}{\partial w}=-\left(\frac{p-(1-k) R \bar{p}}{p^{2}}+k\right) \underbrace{\left(\frac{\partial p}{\partial w}\right)}_{>0} .
$$

Hence, for $k>\overline{\bar{k}},\left(\frac{\partial h}{\partial w}\right)$ has the opposite sign with the expression $\left[\underline{p}-(1-k) R \bar{p}+k p^{2}\right]$. Hence, in this region, for $\left[\underline{p}-(1-k) R \bar{p}+k p^{2}\right]>0,{ }^{17}$ we have $\frac{\partial h}{\partial w}<0$, which means that there is a unique $w^{*}$ that satisfies the indifference equation (13).

Next we show that $w^{*} \in\left(0, \frac{\underline{p}}{1+\underline{p}}\right)$.

First, we show that $w^{*} \geqslant \frac{\underline{p}}{1+\underline{p}}$ cannot be an equilibrium. In that case, price never falls below $\underline{p}$ and $E\left(\pi_{a}\right)=0$, and $E\left(\pi_{i}\right)=E[\alpha R+(1-\alpha) \underline{p}-1]>0$. Hence, $w^{*} \geqslant \frac{\underline{p}}{1+\underline{p}}$ cannot be an equilibrium as some arbitrageurs would deviate and become insiders.

For $w=0$, we have

$$
\begin{aligned}
& p^{*}(k)=\left\{\begin{array}{cc}
\bar{p} & \text { for } k \leqslant \underline{k} \\
\frac{(1-k) R}{k} & \text { for } k>\underline{k}
\end{array},\right. \text { and } \\
& E\left(\pi_{i}\right)=E\left[\frac{\alpha R \bar{p}}{p}+(1-\alpha) p-1\right]=E[\alpha R+(1-\alpha) \bar{p}-1],
\end{aligned}
$$

where $\pi_{i}=\alpha R+(1-\alpha) \bar{p}-1$ for $\alpha \in[0,1]$. Note that $\frac{d \pi_{i}}{d \alpha}<0$ since $R>\bar{p}$. Furthermore, $E\left(\pi_{i}\right)<R$, and hence bounded.

For $w=0$, we have

$$
E\left(\pi_{a}\right)=E\left[[(\underline{p} / p)-1]^{+}\right] .
$$

Note that $\lim _{\alpha \rightarrow 0} p=0$ so that $\lim _{\alpha \rightarrow 0}(\underline{p} / p)=+\infty$. Hence, if the probability distribution $f(\alpha)$ is such that it does not converge to 0 "too fast", then $\lim _{\alpha \rightarrow 0}(\underline{p} / p) f(\alpha)=+\infty$ so that $E\left(\pi_{a}\right)=$ $+\infty .^{18}$ Formally, for $w=0$, we have $\underline{p} / p=(\underline{p} / R)\left(\frac{\alpha \rightarrow 0}{\alpha}-1\right)$, which converges to $+\infty$ as $\alpha$

${ }^{17} \mathrm{~A}$ sufficient condition for this inequality to hold is $\bar{p}<\frac{R-\Delta}{R-1}$. For $k=1$, we have $\left[\underline{p}-(1-k) R \bar{p}+k p^{2}\right]=$ $\underline{p}+p^{2}>0$. Note that $\left[\underline{p}-(1-k) R \bar{p}+k p^{2}\right]>[\underline{p}-(1-k) R \bar{p}]$, which are both increasing in $k$, and the inequality $[\underline{p}-(1-\overline{\bar{k}}) R \bar{p}]>0$ is a sufficient condition. Note that the minimum value $\overline{\bar{k}}$ can take is $\frac{R}{R+\underline{p}}$, which is when $w=0$. We have $\underline{p}-(1-\overline{\bar{k}}) R \bar{p} \geqslant \underline{p}-\left(\frac{\underline{p}}{R+\underline{p}}\right) R \bar{p}$. And, we can show that $\underline{p}-\left(\frac{\underline{p}}{R+\underline{p}}\right) R \bar{p}>0$, for $\bar{p}<\frac{R-\Delta}{R-1}$.

${ }^{18}$ Note that for all continous $f$ that converge to a positive value as $\alpha$ converges to 0 , we have $\lim _{\alpha \rightarrow 0}$ $(\underline{p} / p) f(\alpha)=+\infty$ so that $E\left(\pi_{a}\right)=+\infty$. 
converges to 0 . Even though $f(\alpha)$ can converge to 0 as $\alpha$ converges to 0 , as long as $f(\alpha)$ has an order of $\alpha$ less than 1 , we have $\lim _{\alpha \rightarrow 0}(\underline{p} / p) f(\alpha)=+\infty .{ }^{19}$

Hence $w=0$ cannot be an equilibrium as someone would deviate and take advantage of the potential profits from fire sales. Hence, in equilibrium, we have a unique in equilibrium $w^{*} \in(0,1) . \diamond$

\section{Proof of Proposition 2:}

Part (i): Note that $\frac{\partial h(\alpha, w)}{\partial \alpha}<0\left(\right.$ that is, $\left.\frac{\partial h(k, w)}{\partial k}>0\right)$ is a sufficient condition for $E_{f}[h(\alpha, w)]>$ $E_{g}[h(\alpha, w)]$ when $g$ FOSD $f$, where $E_{f}$ and $E_{g}$ represent expectations over probability distributions $f$ and $g$, respectively. We already showed that $\frac{\partial E[h(\alpha, w)]}{\partial w}<0$, so that it is sufficient to show $\frac{\partial h(k, w)}{\partial k}>0$ to prove the result. To do that, we look at the four possible regions for $k$.

(1) For $k \leqslant \underline{k}$, we have $p=\bar{p}$, which gives us $h(k, w)=-(1-k) R-k \bar{p}+1$. Hence, $\frac{\partial h}{\partial k}=R-\bar{p}>0$.

(2) For $k \in(\underline{k}, \bar{k}]$, we have $p=\frac{(1-k) R}{k}$, which gives us

$$
h(k, w)=-(1-k)\left(\frac{R \bar{p}}{p}\right)-k p+1=-k \bar{p}-(1-k) R+1 .
$$

Hence, $\frac{\partial h}{\partial k}=R-\bar{p}>0$.

(3) For $k \in(\bar{k}, \overline{\bar{k}}]$, we have $p=\underline{p}$, and

$$
h(k, w)=-(1-k)\left(\frac{R \bar{p}}{\underline{p}}\right)-k \underline{p}+1, \text { which gives us } \frac{\partial h}{\partial k}=\frac{R \bar{p}}{\underline{p}}-\underline{p}>R-\bar{p}>0 .
$$

(4) For $k>\overline{\bar{k}}$, we have $p=\frac{(1-w)(1-k) R+w}{(1-w) k}$, and

$$
h(k, w)=\frac{(1-w) k \underline{p}-(1-w) k(1-k) R \bar{p}-(1-w)(1-k) R-w}{(1-w)(1-k) R+w}-(1-k) R-\frac{w}{(1-w)}+1 .
$$

Note that, in the above expression, the denominator of the first term is decreasing in $k$, whereas the second term is increasing in $k$. Hence, if the numerator of the first expression is increasing in $k$, then it is sufficient for $\frac{\partial h(k, w)}{\partial k}>0$. The derivative of the numerator of the first expression with respect to $k$ is given as:

$$
(1-w)[\underline{p}-(1-k) R \bar{p}+k R \bar{p}+R]=(1-w)[\underline{p}-R \bar{p}+2 k R \bar{p}+R] .
$$

\footnotetext{
${ }^{19}$ For $f$ that has an order of $\alpha$ greater than 1 and $\lim _{\alpha \rightarrow 0} f(\alpha)=0$, we have $\lim _{\alpha \rightarrow 0}(\underline{p} / p) f(\alpha)=0$, so that, for $w=0$, we have $E\left(\pi_{a}\right)<+\infty$. Under such probability distributions, it is possible to have no arbitrage capital $(w=0)$ in equilibrium. For example $f(\alpha)=(a+1) \alpha^{a}$, for $\alpha \in[0,1]$ and $a>1$, would give such a result.
} 
Next, we show that, for $R>\underline{p}$, we have $[\underline{p}-R \bar{p}+2 k R \bar{p}+R]>0$.

Let $A=\underline{p}-R \bar{p}+2 k R \bar{p}+R$. We have $\frac{\partial A}{\partial k}=2 R \bar{p}>0$. Hence, if $A>0$ for $k=\overline{\bar{k}}$, we have $A>0$ for all $k>\overline{\bar{k}}$.

We have $\frac{d \overline{\bar{k}}}{d w}=\frac{1}{(1-w)^{2}(R+\underline{p})}>0$. Hence, if we can show that $A>0$ for $k=\overline{\bar{k}}$ and $w=0$, we are done. For $w=0$, we have $\overline{\bar{k}}=\frac{R}{R+\underline{p}}$, which gives us $A=\underline{p}-R \bar{p}+2\left(\frac{R}{R+\underline{p}}\right) R \bar{p}+R$. For $R>\underline{p}$, we have $\frac{R}{R+\underline{p}}>\frac{1}{2}$ so that $A>\underline{p}+R>0$.

Hence, we have $\frac{\partial h(k, w)}{\partial k}>0$.

Part (ii): From the indifference equation (13), we have $E_{\alpha}\left[h\left(\alpha, w^{*}\right)\right]=0$. Thus, we have

$$
\frac{\partial E\left[h\left(\alpha, w^{*}\right)\right]}{\partial w} \cdot \frac{d w^{*}}{d \Delta}+\frac{\partial E\left[h\left(\alpha, w^{*}\right)\right]}{\partial \Delta}=0 .
$$

We already showed that $\left(\frac{\partial E\left[h\left(\alpha, w^{*}\right)\right]}{\partial w}\right)<0$, so that

$$
\operatorname{sign}\left(\frac{d w^{*}}{d \Delta}\right)=\operatorname{sign}\left(\frac{\partial E\left[h\left(\alpha, w^{*}\right)\right]}{\partial \Delta}\right) \text {. }
$$

Hence, we need to show that $\left(\frac{\partial E\left[h\left(\alpha, w^{*}\right)\right]}{\partial \Delta}\right)<0$. Note that the price $p^{*}(k)$ given in equation (9) is continuous in $\Delta$. Hence, $h\left(k, w^{*}\right)$ is continuous in $\Delta$. Thus, using Leibnitz's rule, we can show that

$$
\frac{\partial E(h)}{\partial \Delta}=\int_{k=0}^{1}\left(\frac{\partial h}{\partial \Delta}\right) f(k) d k .
$$

Next, we analyze each of the four regions of $k$ given in equation (9). Note that for $k \leqslant \bar{k}$, price $p(k, w)$ is independent of $\Delta$. This, in turn, implies that for $k \leqslant \bar{k}, h(\cdot)$ is independent of $\Delta$.

For $k \in(\bar{k}, \overline{\bar{k}}]$, we have $p(k, w)=\underline{p}$, where $\frac{\partial \underline{p}}{\partial \underline{\Delta}}=-1<0$. For $k \in[\bar{k}, \overline{\bar{k}}]$, we have

$$
h\left(k, w^{*}\right)=-(1-k)\left(\frac{R \bar{p}}{\underline{p}}\right)-k \underline{p}+1, \text { which gives us } \frac{\partial h}{\partial \underline{p}}=(1-k)\left(\frac{R \bar{p}}{\underline{p}^{2}}\right)-k .
$$

Note that $\frac{\partial h}{\partial \underline{p}}$ is decreasing in $k$. Hence, if $\frac{\partial h}{\partial \underline{p}} \geqslant 0$ for $k=\overline{\bar{k}}$, then $\frac{\partial h}{\partial \underline{p}}>0$ for all $k \in[\bar{k}, \overline{\bar{k}})$. Furthermore, we have $\frac{\partial h}{\partial \underline{p}}=(1-k)\left(\frac{R \bar{p}}{\underline{p}^{2}}\right)-k=0$ when $k=\widehat{k}=\frac{R \bar{p}}{R \bar{p}+\underline{p}^{2}}$. Hence, if $\overline{\bar{k}}<\widehat{k}$, then $\frac{\partial h}{\partial \underline{p}}>0$ for all $k \in[\bar{k}, \overline{\bar{k}}]$. We have $\overline{\bar{k}}<\widehat{k}$ if and only if

$$
\frac{(1-w) R+w}{(1-w)(R+\underline{p})}<\frac{R \bar{p}}{R \bar{p}+\underline{p}^{2}}
$$


which holds if and only if $w<\widehat{w}=\frac{R \underline{p} \Delta}{R \underline{p} \Delta+R \bar{p}+\underline{p}^{2}}$.

This, combined with the fact that $\frac{\partial \underline{p}}{\partial \Delta}<0$, gives us $\frac{\partial h}{\partial \Delta}<0$, for $k \in(\bar{k}, \overline{\bar{k}}]$.

For $k>\overline{\bar{k}}$, the price $p^{*}$ is independent of $\Delta$ as all the funds within the surviving insiders and arbitrageurs are exhausted. Hence, for $k>\overline{\bar{k}}, \frac{\partial h}{\partial \Delta}=0$.

Combining these results, we get $\left(\frac{\partial E(h)}{\partial \Delta}\right)<0$.

Proof of Proposition 3: We have

$y_{I}=\left\{\begin{array}{ccc}(1-w) k & \text { for } \quad k \leqslant \underline{k} \\ (1-w) k & \text { for } \quad k \in(\underline{k}, \bar{k}] \\ \frac{(1-w)(1-k) R}{\underline{p}} & \text { for } k \in(\bar{k}, \overline{\bar{k}}] \\ \frac{(1-w)^{2} k(1-k) R}{(1-w)(1-k) R+w} & \text { for } & k>\overline{\bar{k}}\end{array} \quad\right.$ and $\quad y_{A}=\left\{\begin{array}{ccc}0 & \text { for } & k \leqslant \underline{k} \\ 0 & \text { for } & k \in(\underline{k}, \bar{k}] \\ (1-w)\left[k-\frac{(1-k) R}{\underline{p}}\right] & \text { for } & k \in(\bar{k}, \overline{\bar{k}}] \\ \frac{w(1-w) k}{(1-w)(1-k) R+w} & \text { for } & k>\overline{\bar{k}}\end{array}\right.$.

Note that for $w=0, E(\Pi)$ assumes its maximum value of

$$
E(\Pi)=E[\alpha(R+\bar{p})+(1-\alpha) \bar{p}] .
$$

Hence, the socially optimal level of arbitrage capital is zero, that is, $w^{* *}=0$.

\section{Proof of Proposition 4:}

The steps of the proof are organized in a way that lays down the results for different regions of the proportion $(k)$ of failed insiders.

(1) For $k \leqslant \widehat{k}$, liquidity within the surviving insiders and the liquidity they can raise by issuing shares to arbitrageurs is sufficient to sustain the price for the failed insiders' assets at $\bar{p}$.

Since $p^{*}(k)=\bar{p}>\underline{p}$, we have $x=0$ and $m=\frac{k}{1-k}$. Each surviving insider issues enough equity, at $q(k)=\bar{p}$, to purchase $\frac{k}{1-k}$ units of failed insiders' assets at $p^{*}(k)=\bar{p}$. Thus, we have

$$
\begin{aligned}
& R+s \bar{p}=\left(\frac{k}{1-k}\right) \bar{p}, \text { which gives us: } \\
& s=\frac{k}{1-k}-\frac{R}{\bar{p}} \quad \text { and } \quad z=k-\frac{(1-k) R}{\bar{p}} .
\end{aligned}
$$


(2) For $\widehat{k}<k \leqslant \overline{\bar{k}}$, liquidity within the surviving insiders and the liquidity they can raise through equity issuance from arbitrageurs is sufficient to sustain $p^{*}(k)$ at least at $\underline{p}$.

Since $p^{*}(k) \geqslant p$, we have $x=0$ and $m=\frac{k}{1-k}$. Each surviving insider issues enough equity, at $q(k)=\bar{p}$, to purchase $\frac{k}{1-k}$ units of failed insiders' assets at $p^{*}(k)=\frac{(1-k) R+w}{k}$, that is,

$$
\begin{aligned}
R+s \bar{p} & =\left(\frac{k}{1-k}\right) p^{*}(k), \text { which gives us } \\
s & =\frac{k}{1-k} \quad \text { and } \quad z=k .
\end{aligned}
$$

(3) For $k>\overline{\bar{k}}$, total liquidity within the surviving insiders and the liquidity they can raise through equity issuance from arbitrageurs is no longer sufficient to sustain $p^{*}(k)$ at $\underline{p}$. Since $p^{*}(k)<\underline{p}$, arbitrageurs may prefer to participate in the market for failed insiders' assets.

If $p^{*}(k)<\underline{p}$ and $\underline{p} q(k)>\bar{p} p^{*}(k)$, then arbitrageurs use all their funds for the asset purchase, that is $x=\frac{w}{p^{*}(k)}$.

If $p^{*}(k)<\underline{p}$ and $\underline{p} q(k)<\bar{p} p^{*}(k)$, then arbitrageurs use all their funds for the equity purchase, that is $y=\frac{w}{q(k)}$, and if $\underline{p} q(k)=\bar{q} p^{*}(k)$, arbitrageurs are indifferent between the purchase of surviving insiders' shares and the failed insiders' assets.

Now, let $\mu=\frac{\bar{p}}{\underline{p}}$. Whether arbitrageurs buy shares of the surviving insiders or the assets of the failed insiders, their entire funds $w$ eventually end up in the asset market. Hence, for $k>\overline{\bar{k}}$, the price for failed insiders' assets is given as:

$$
p^{*}(k)=\frac{(1-k) R+w}{k} .
$$

If the price $q(k)$ of a share is higher then $\mu p^{*}(k)$, then arbitrageurs are better off buying the assets of failed insiders, rather than buying shares of the surviving insiders, that is, $y=0$ and $x=\frac{w}{p^{*}(k)}$. Hence, we cannot have an equilibrium where $q(k)>\mu p^{*}(k)$ and $y>0$.

Next, we show that surviving insiders need to suffer some discount when they generate funds in the capital market. Note that arbitrageurs are willing to purchase shares of surviving insiders, that is, $y>0$, only when $q(k) \leqslant \mu p^{*}(k)$ and surviving insiders are willing to issue equity, that is, $s>0$, only when $q(k) \geqslant p^{*}(k)$. Suppose that the market-clearing mechanism works in a way that allows the maximum possible funds to go to insiders through equity issuance, that is $q(k)=\mu p^{*}(k)$. Note that this allows for the highest price $q(k)$ for shares. However, even in this case, surviving insiders need to suffer some discount when they generate funds in the capital market. Hence, in equilibrium, for $k>\overline{\bar{k}}$, we have $q(k)=\mu p^{*}(k)<\bar{p}$. $\diamond$ 
Proof of Proposition 6: In equilibrium, we have $p_{i}=p_{j}$, which gives us

$$
\frac{\left(1-k_{i}\right) R+w_{i}}{k_{i}}=\frac{\left(1-k_{j}\right) R+\left(w-w_{i}\right)}{k_{j}} .
$$

Using this condition, we can show that the equilibrium level of arbitrageurs' funds that is channelled to country $i$ is given as

$$
w_{i}^{*}=\max \left\{0,\left(\frac{k_{i}(R+w)-k_{j} R}{k_{i}+k_{j}}\right)\right\} .
$$

We have

$$
\frac{d w_{i}^{*}}{d k_{i}}=\frac{(2 R+w) k_{j}}{\left(k_{i}+k_{j}\right)^{2}}>0 \text { and } \frac{d w_{i}^{*}}{d k_{j}}=-\frac{k_{i}(2 R+w)}{\left(k_{i}+k_{j}\right)^{2}}<0 . \diamond
$$




\section{Appendix II}

In the analysis so far, insiders are more efficient in running assets. This is because of the expertise insiders gain through learning-by-doing. In this section, we allow for experts and non-experts in the model and we analyze which set of agents choose to become insiders as opposed to arbitrageurs. Below, we analyze two different models where in Model I experts become insiders, whereas in Model II experts stay as arbitrageurs.

Model I: This case is very similar to the case we analyzed so far. We have the expected returns for insiders and arbitrageurs as given in equations (11) and (12), respectively. Thus, the equilibrium level of arbitrageur capital, denoted by $w_{1}^{*}$ satisfies the condition:

$$
E[\alpha R]=\underbrace{E\left[\frac{1}{p}(\underline{p}-p)^{+}-\alpha\left[\frac{R}{p}(\bar{p}-p)\right]-(1-\alpha) p+1\right]}_{=F\left(w_{1}^{*}\right)}
$$

where $p$ is given in equation (9).

Model II: In this case, non-experts become insiders and experts stay as arbitrageurs. First, we derive the price function for failed insiders' assets. Note that, as experts are arbitrageurs in this case, the first set of failed insiders' assets will be purchased by arbitrageurs and surviving insiders will start purchasing assets only when the price falls below $\underline{p}$.

Let $w_{2}$ be the fraction that are experts and stay as arbitrageurs. And the rest, a fraction $\left(1-w_{2}\right)$, are non-experts that are insiders. Let $k_{2}$ be the fraction of insiders that fail at $t=1$. Note that the resources available with each surviving insider for purchasing and running the failed insiders' assets, denoted by $\widehat{R}$, equal $\widehat{R}=R-\widehat{\Delta}$.

For $p<\bar{p}$, the optimal demand schedule for arbitrageurs is $y_{a}(p)=\frac{w_{2}}{p_{2}}$. For $p>\bar{p}$, the demand is $y_{a}(p)=0$, and for $p=\bar{p}, y_{a}(p)$ is indeterminate.

For $p<\underline{p}$, surviving insiders' demand schedule is $y(p)=\frac{\widehat{R}}{p_{2}}$. For $p>\underline{p}$, the demand is $y(p)=0$, and for $p=\underline{p}, y(p)$ is indeterminate.

The price $p$ cannot exceed $\bar{p}$ since in this case we have $y(p)=y_{a}(p)=0$. If $p \leqslant \bar{p}$, and the proportion of failed insiders is sufficiently small, arbitrageurs have enough funds to pay the full price for all assets. More specifically, for $k \leq \underline{k}_{2}$, where $\underline{k}_{2}=\frac{w_{2}}{\left(1-w_{2}\right) \bar{p}}$, the auction price is set at $p^{*}=\bar{p}$ and a share $y_{a}\left(p_{2}^{*}\right)=\frac{k_{2}}{w_{2}}$ is allocated to each arbitrageur.

For moderate values of $k_{2}$, arbitrageurs cannot pay the full price for all assets but can still pay at least the threshold value of $\underline{p}$. Formally, for $k \in(\underline{k}, \bar{k}]$, where $\bar{k}_{2}=\frac{w_{2}}{\left(1-w_{2}\right) \underline{p}}$, the price is set at $p_{2}^{*}=\frac{w_{2}}{\left(1-w_{2}\right) k}$, and again, all assets are acquired by arbitrageur.

For $k_{2}>\bar{k}_{2}$, arbitrageurs cannot pay the threshold price of $\underline{p}$ for all assets and profitable options emerge for surviving insiders. Hence, for $k_{2}>\bar{k}_{2}$, surviving insiders have a positive 
demand. With the injection of surviving insiders' funds, price can be sustained at $\underline{p}$ until some critical proportion of failures $\overline{\bar{k}}_{2}>\bar{k}_{2}$. However, for $k_{2}>\overline{\bar{k}}_{2}$, even the injection of insider capital is not enough to sustain the price at $\underline{p}$. Formally, for $k \in(\bar{k}, \overline{\bar{k}}]$, where

$$
\overline{\bar{k}}_{2}=\min \left\{1,\left(\frac{w_{2}+\left(1-w_{2}\right) \widehat{R}}{\left(1-w_{2}\right)[\widehat{R}+\underline{p}]}\right)\right\}
$$

the price is set at $\underline{p}$, and a share of $y_{a}(\underline{p})=\frac{w_{2}}{\underline{p}}$ is allocated to arbitrageurs while the rest, $y(\underline{p})=\left(1-w_{2}\right) k_{2}-\frac{w_{2}}{\underline{p}}$, is allocated to surviving insiders.

And, for $k_{2}>\overline{\bar{k}}_{2}$, the price is again strictly decreasing in $k_{2}$ and is given by

$$
p_{2}^{*}\left(k_{2}\right)=\frac{\left(1-k_{2}\right) \widehat{R}}{k_{2}}+\frac{w_{2}}{\left(1-w_{2}\right) k_{2}}
$$

and $y\left(p_{2}^{*}\right)=\frac{\widehat{R}}{p_{2}^{*}}$ and $y_{a}\left(p_{2}^{*}\right)=\frac{w_{2}}{p_{2}^{*}}$.

The resulting price function is given as follows:

$$
p_{2}^{*}\left(k_{2}\right)=\left\{\begin{array}{ccc}
\bar{p} & \text { for } & k_{2} \leqslant \underline{k}_{2} \\
\frac{w_{2}}{\left(1-w_{2}\right) k_{2}} & \text { for } & k_{2} \in\left(\underline{k}_{2}, \bar{k}_{2}\right] \\
\underline{p} & \text { for } & k_{2} \in\left(\bar{k}_{2}, \overline{\bar{k}}_{2}\right] \\
\frac{\left(1-k_{2}\right) \widehat{R}}{k_{2}}+\frac{w_{2}}{\left(1-w_{2}\right) k_{2}} & \text { for } & k_{2}>\overline{\bar{k}}_{2}
\end{array} .\right.
$$

Note the difference from the benchmark model : The first set of failed insiders' assets will be purchased by arbitrageurs and surviving insiders will start purchasing assets only when the price falls below $\underline{p}$.

Using the price function in equation (60), we can calculate the expected profit for insiders and arbitrageurs, which gives us the equilibrium condition as follows:

$$
E\left(\pi_{i}\right)=E\left[\alpha\left(\widehat{R}+\frac{\widehat{R}}{p_{2}}\left(\underline{p}-p_{2}\right)^{+}\right)+(1-\alpha) p_{2}-1\right]=E\left[\frac{1}{p_{2}}\left(\bar{p}-p_{2}\right)\right]=E\left(\pi_{a}\right) .
$$

Proposition 7 Let $w_{2}^{*}$ be the equilibrium proportion of arbitrageurs in Model II that is given by the first order condition in equation (61). We have $w_{2}^{*}>w_{1}^{*}$.

Proof: Note that using the first order conditions in equation (57) for Model I and equation (61) in Model II, we have $F\left(w_{1}^{*}\right)=G\left(w_{2}^{*}\right)$, where

$$
E(\alpha R)=\underbrace{E\left[\frac{1}{p_{2}}\left(\bar{p}-p_{2}\right)-\alpha\left(\frac{R-\widehat{\Delta}}{p_{2}}\right)\left(\underline{p}-p_{2}\right)^{+}-(1-\alpha) p_{2}+1+\alpha \widehat{\Delta}\right]}_{=G\left(w_{2}^{*}\right)} .
$$


Also, note that as arbitrageur wealth increases, the price for failed firms' assets increase. This, in turn, leads to a decrease in both $F$ and $G$. Thus, we have $\frac{\partial F}{\partial w_{1}}<0$ and $\frac{\partial G}{\partial w_{2}}<0$.

Next, we can show that for the same level of arbitrageur wealth $w$, we have $G(w)>F(w)$ for all $w$, since $\widehat{R}=(R-\widehat{\Delta})$ and $(\bar{p}-p)>(\underline{p}-p)^{+}$. Furthermore, $G(w)>F(w)$ for all $w$, implies that equilibrium level of arbitrageur capital is higher in Model II, that is, $w_{2}^{*}>w_{1}^{*}$. 


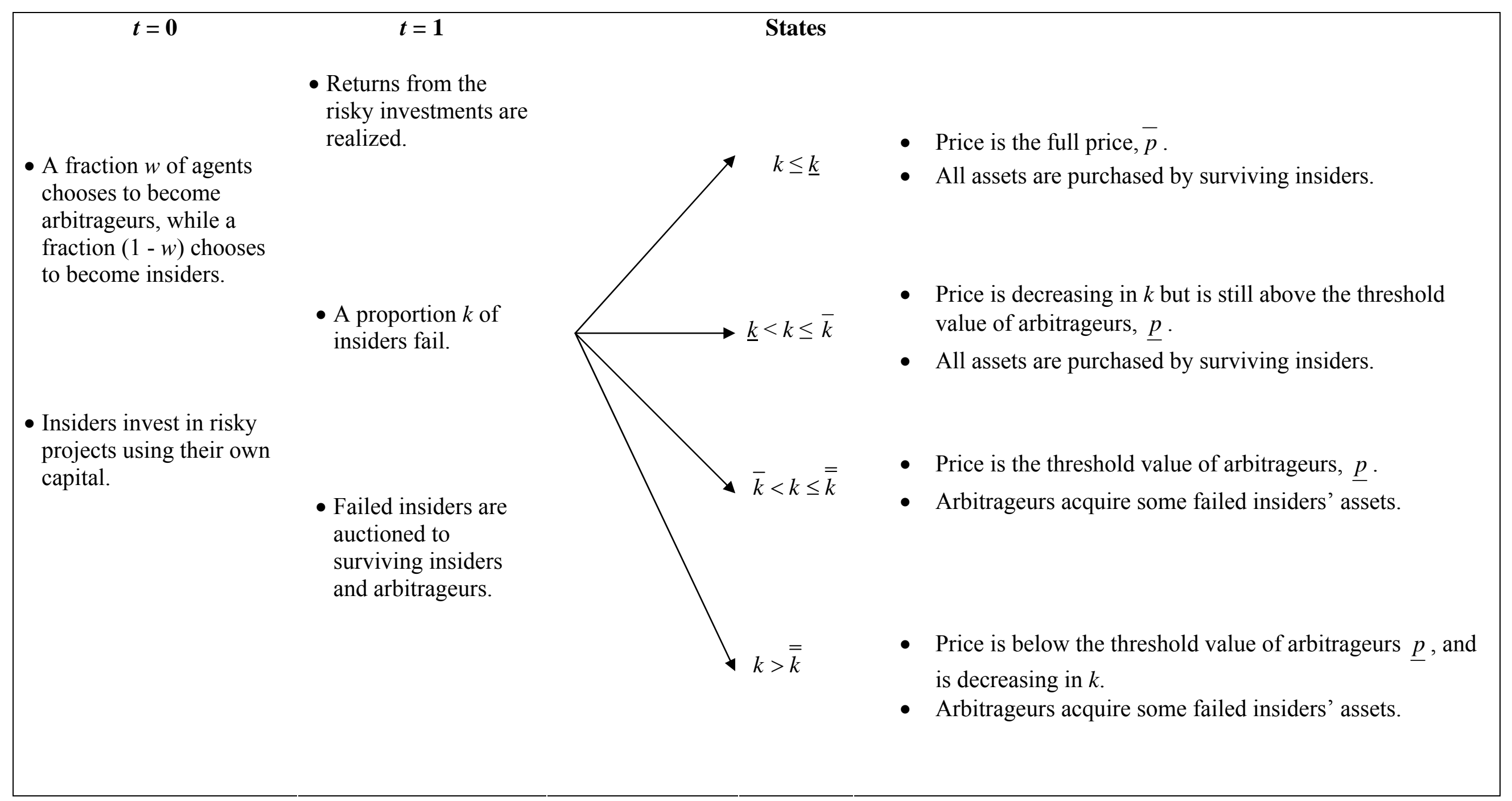

Figure 1: Timeline of the model. 


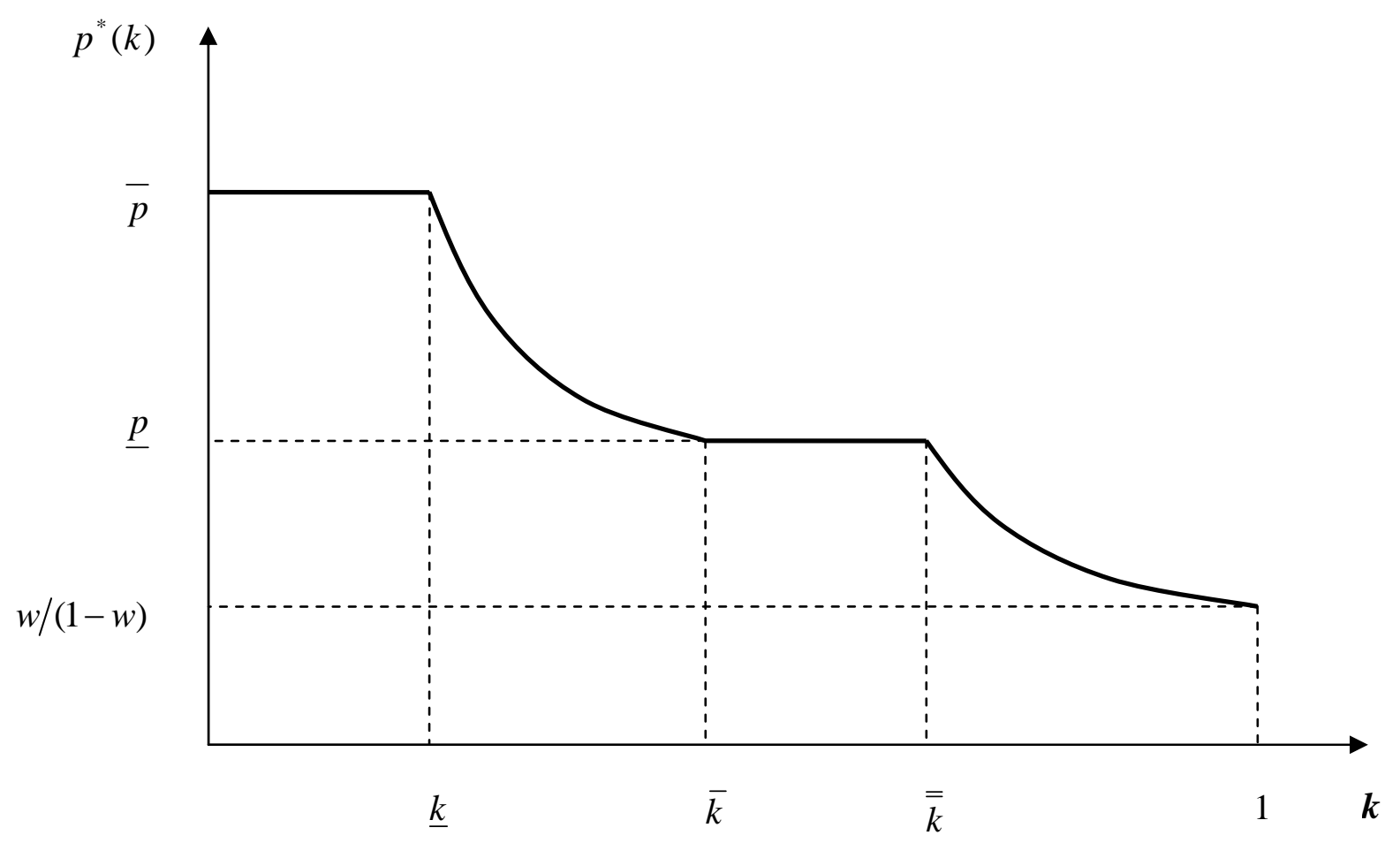

Figure 2: Price function.

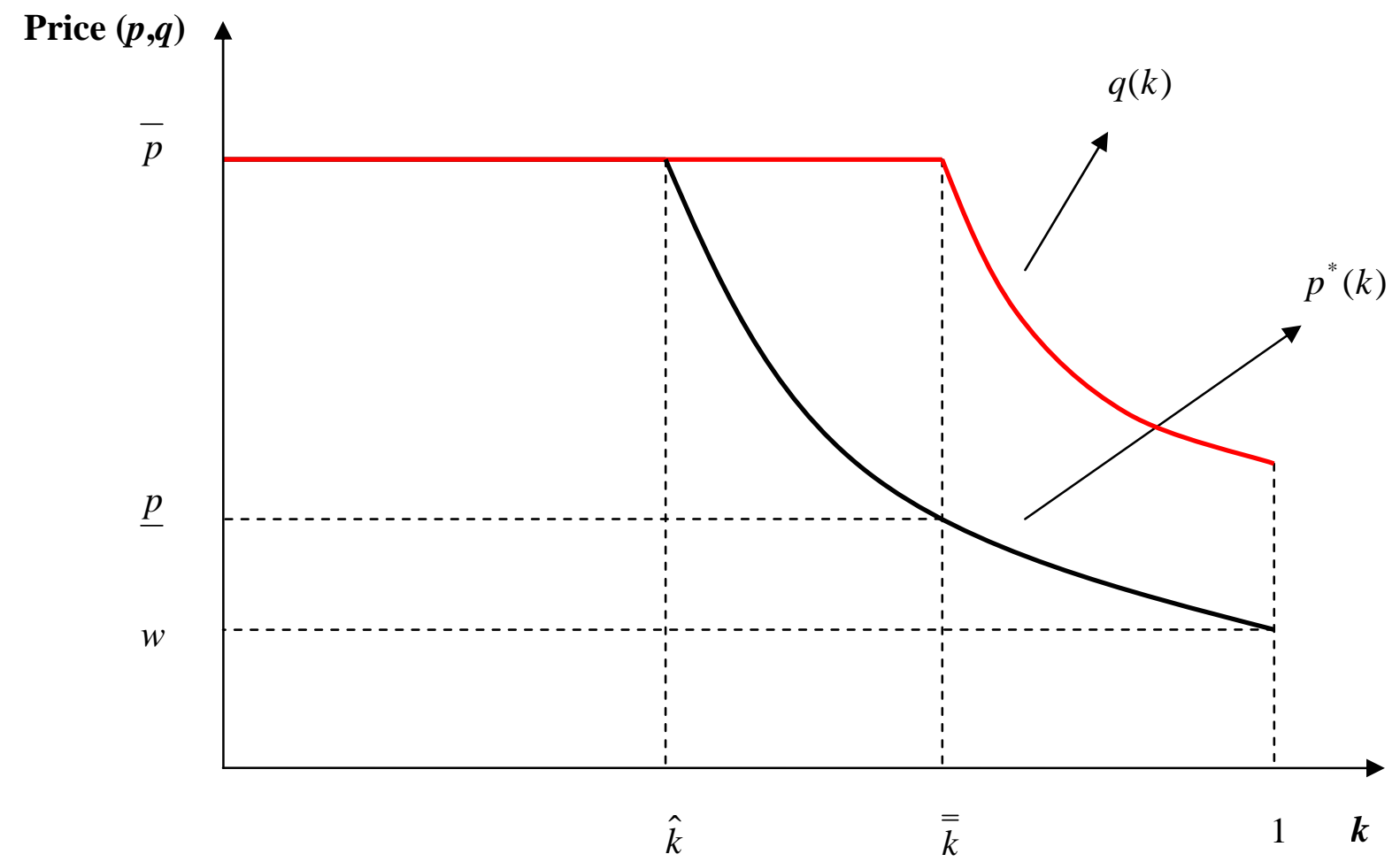

Figure 3: Prices in Proposition 4. 


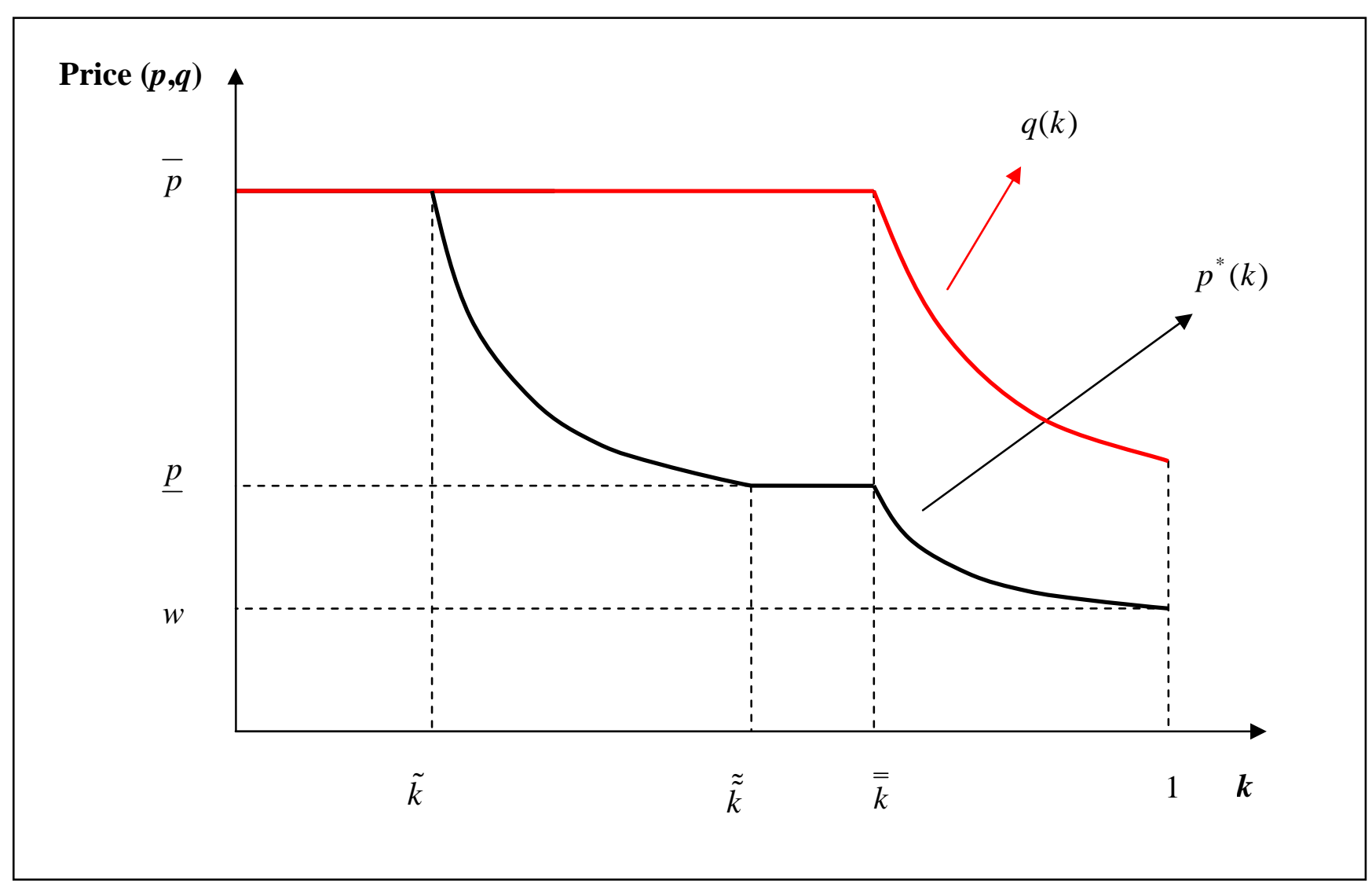

Figure 4: Prices with limited pledgeability.

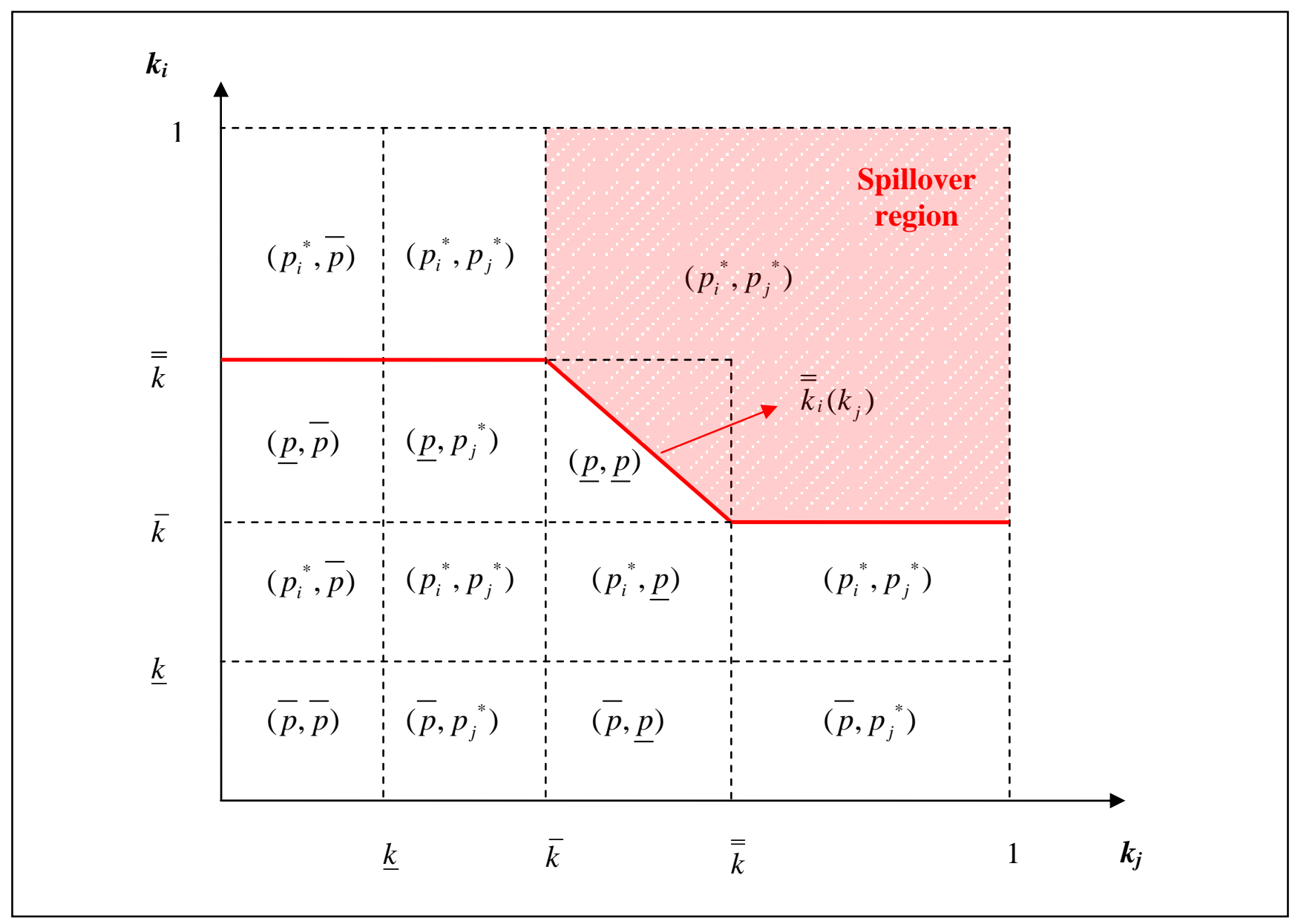

Figure 5: Prices $\left(p_{i}^{*}, p_{j}^{*}\right)$ in Proposition 5. 
Figure 6: Comparative statics on arbitrage capital $\left(w^{\star}\right)$ for Model I

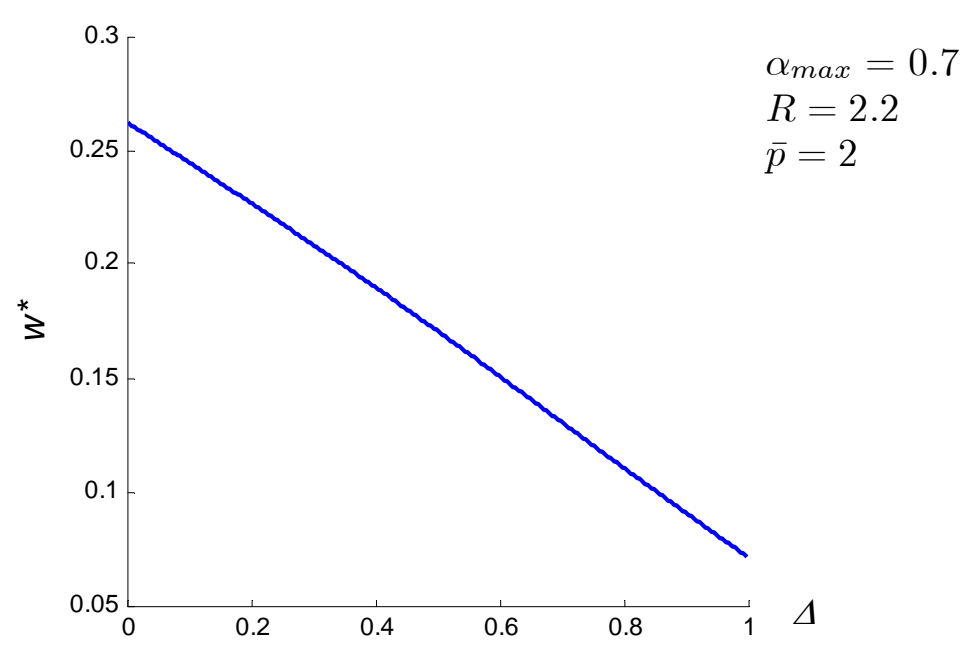

Fig ure 6a: Effect of $\Delta$

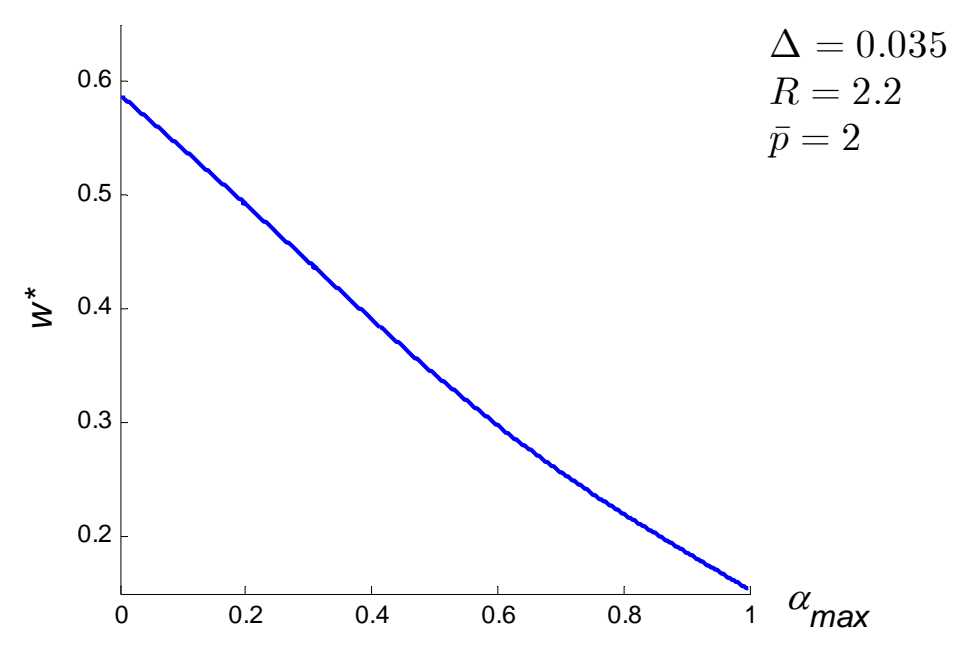

Figure 6b: Effect of $\alpha_{\max }$

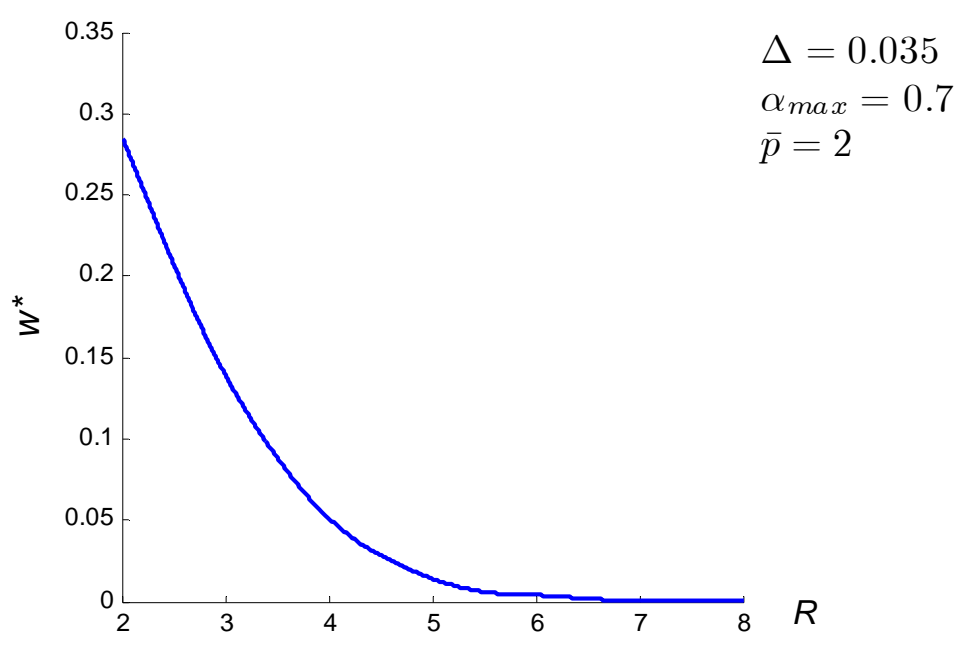

Figure 6c: Effect of $\mathrm{R}$

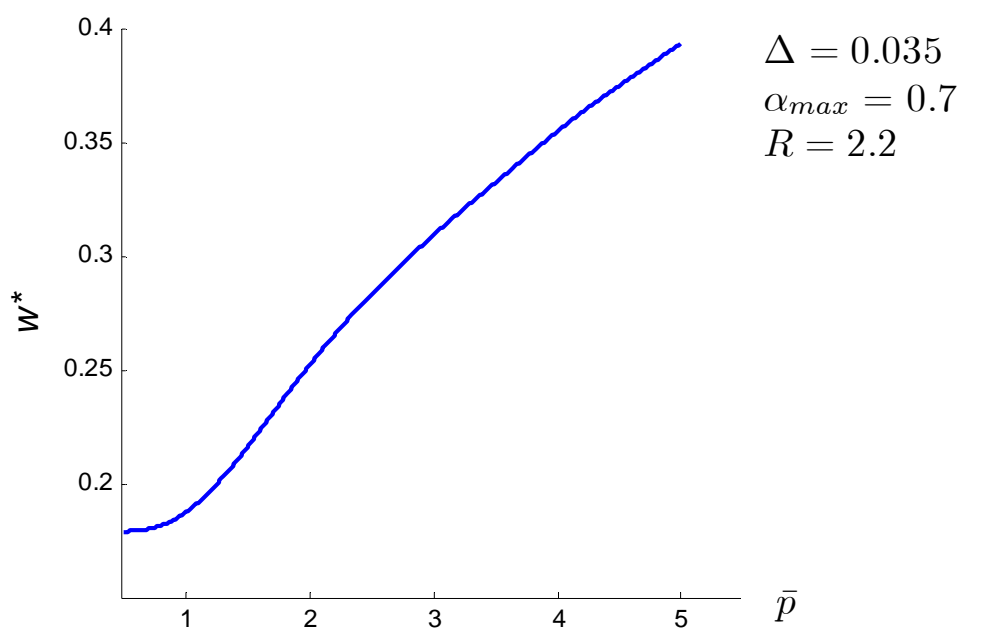

Figure 6d: Effect of $\bar{p}$ 
Figure 7: Comparative statics on expected profits $\left(E\left(\pi^{\star}\right)\right)$ for Model I

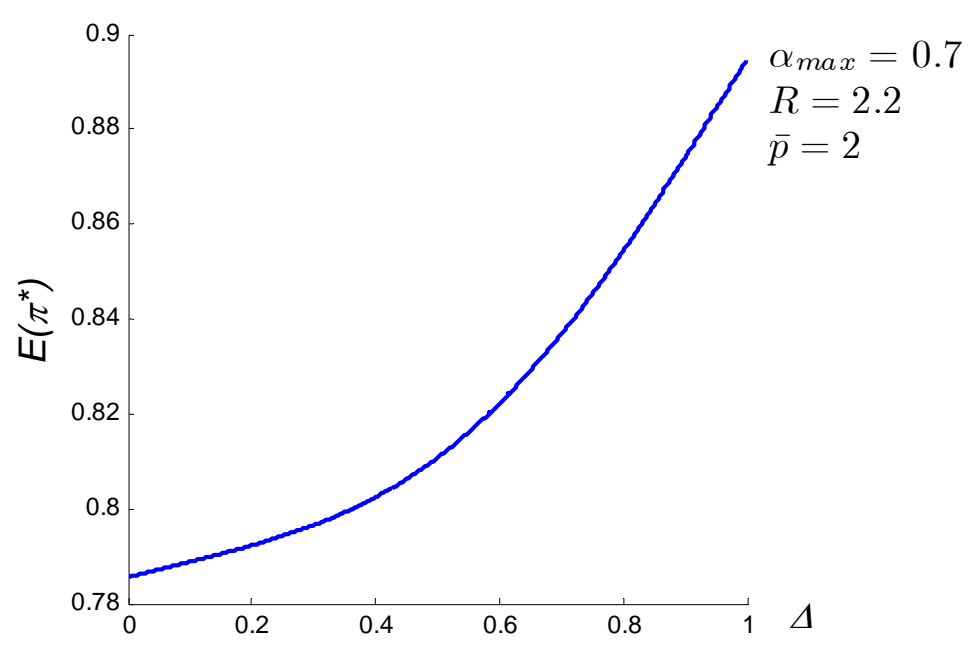

Figure 7a: Effect of $\Delta$

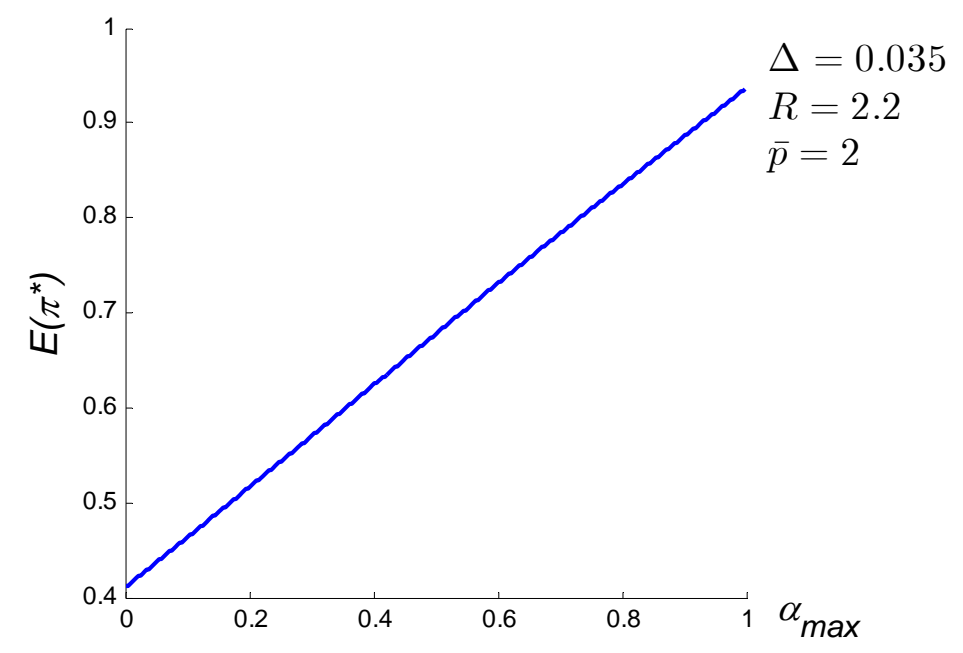

Figure 7b: Effect of $\alpha_{\max }$

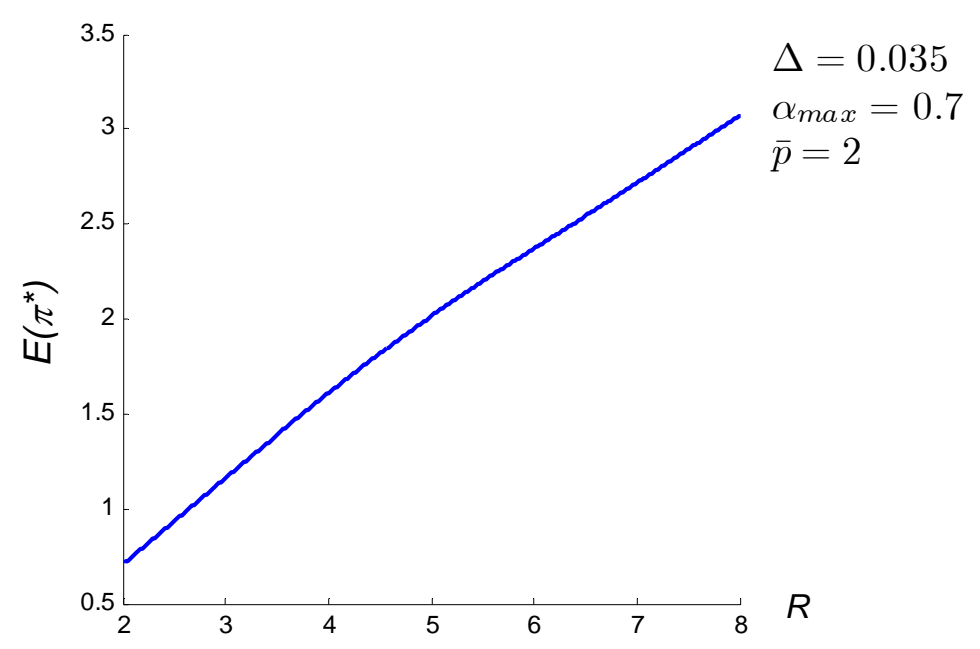

Figure 7c: Effect of $\mathrm{R}$

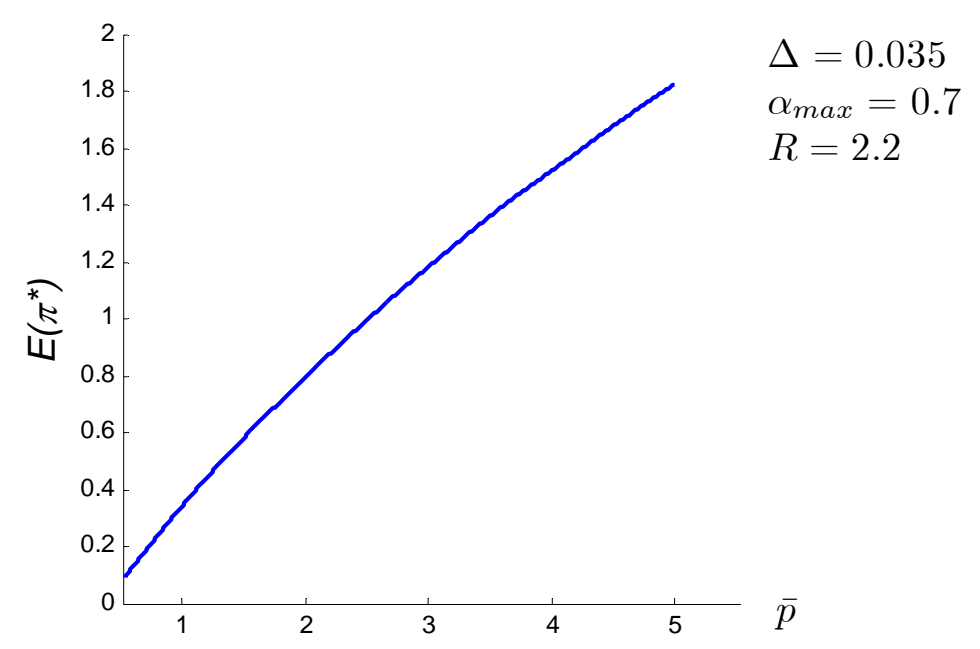

Figure 7d: Effect of $\bar{p}$ 
Figure 8: Comparative statics on arbitrage capital $\left(\mathrm{w}^{\star}\right) \quad$-......... Model I II

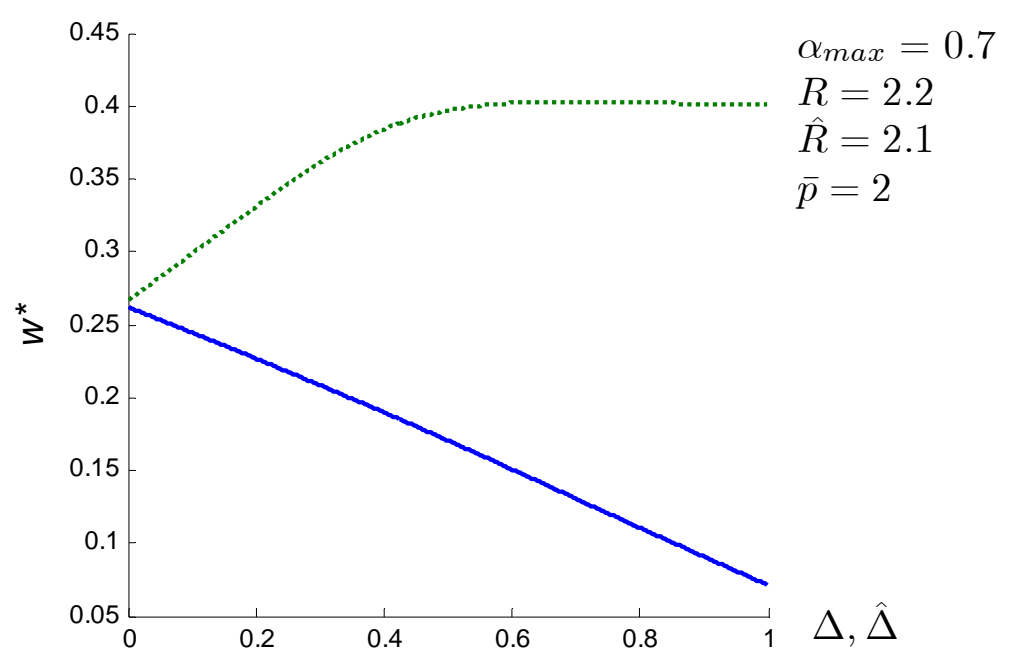

Figure 8a: Effect of $\Delta$ (Model I) and $\hat{\Delta}$ (Model II)

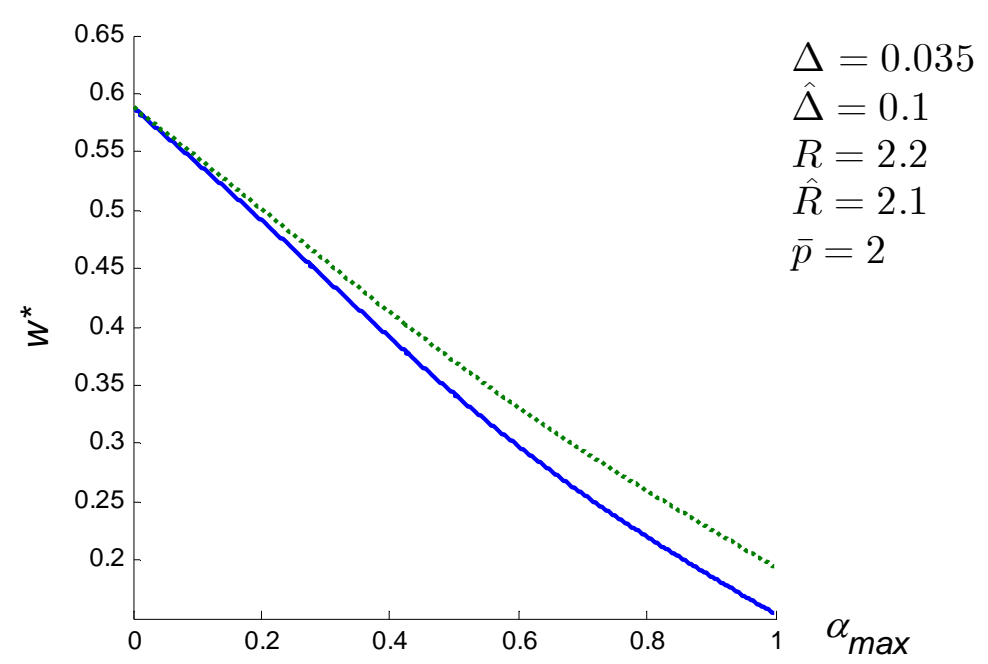

Figure 8b: Effect of $\alpha_{\max }$

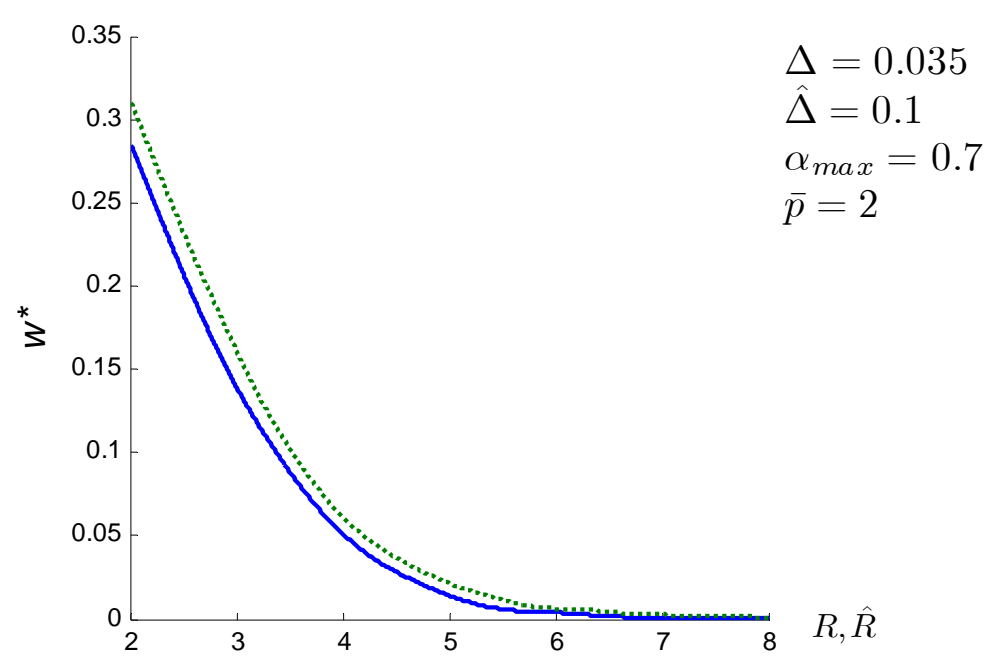

Figure 8c: Effect of $\mathrm{R}$ (Model I) and $\hat{R}$ (Model II)

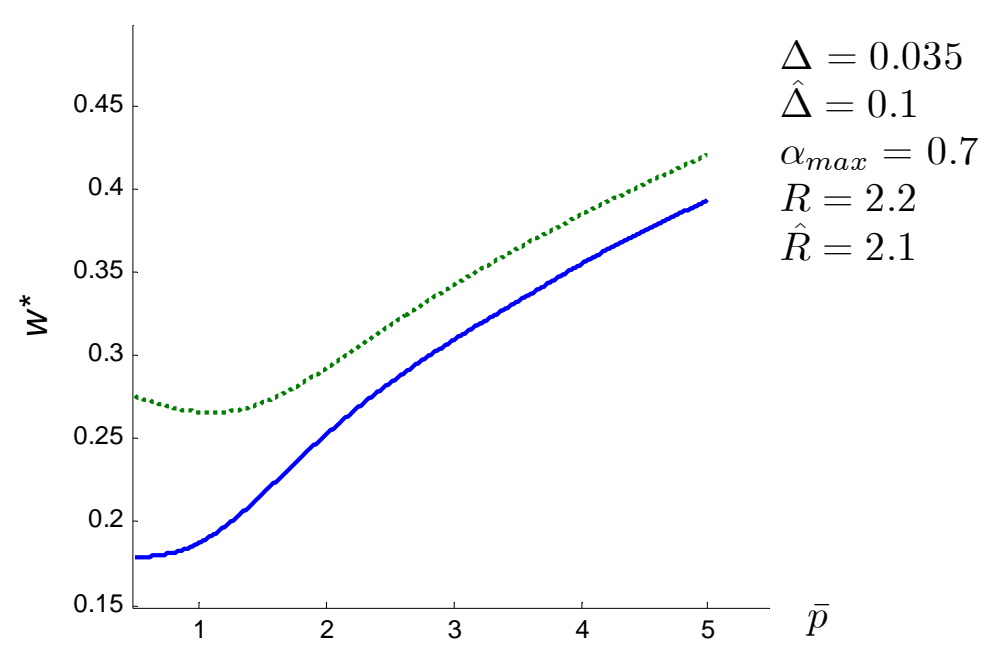

Figure 8d: Effect of $\bar{p}$ 


\section{Figure 9: Comparative statics on expected profits $\left(E\left(\pi^{\star}\right)\right) \quad$-.......... Model I}

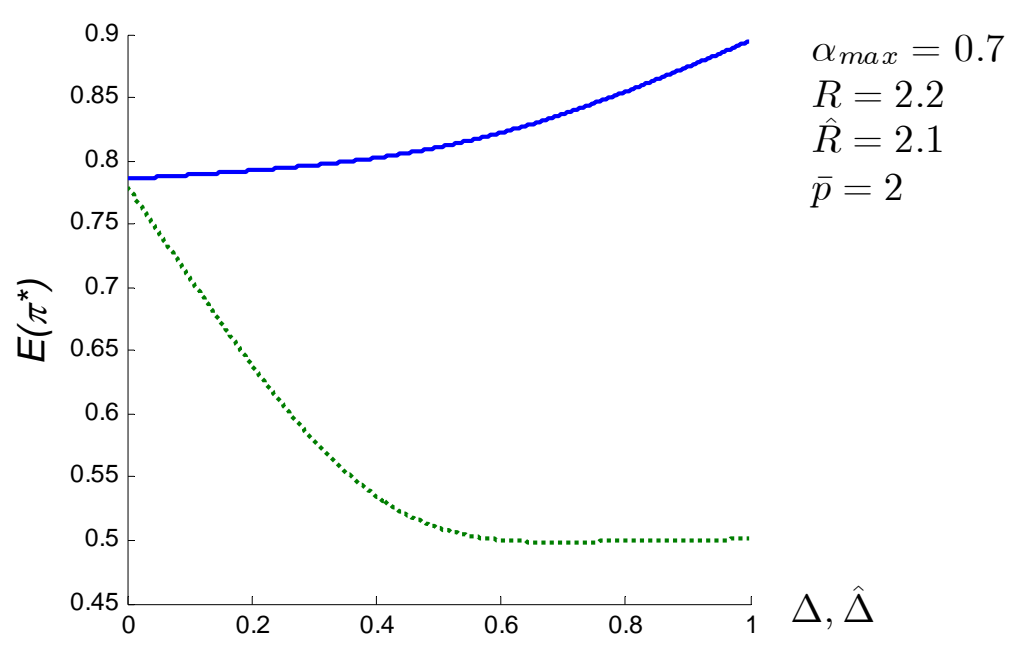

Figure 9a: Effect of $\Delta$ (Model I) and $\hat{\Delta}$ (Model II)

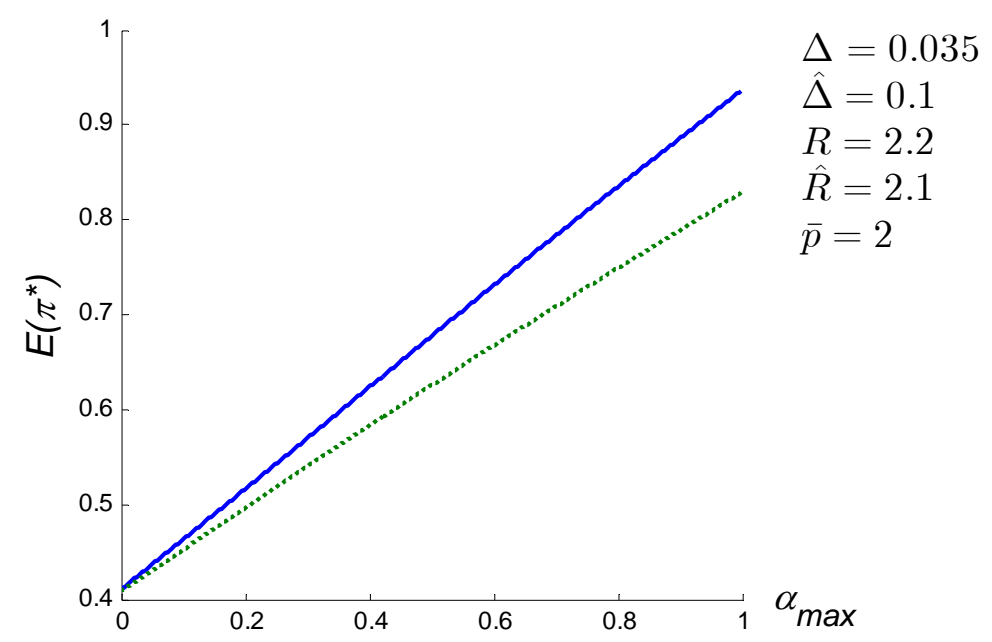

Figure 9b: Effect of $\alpha_{\max }$

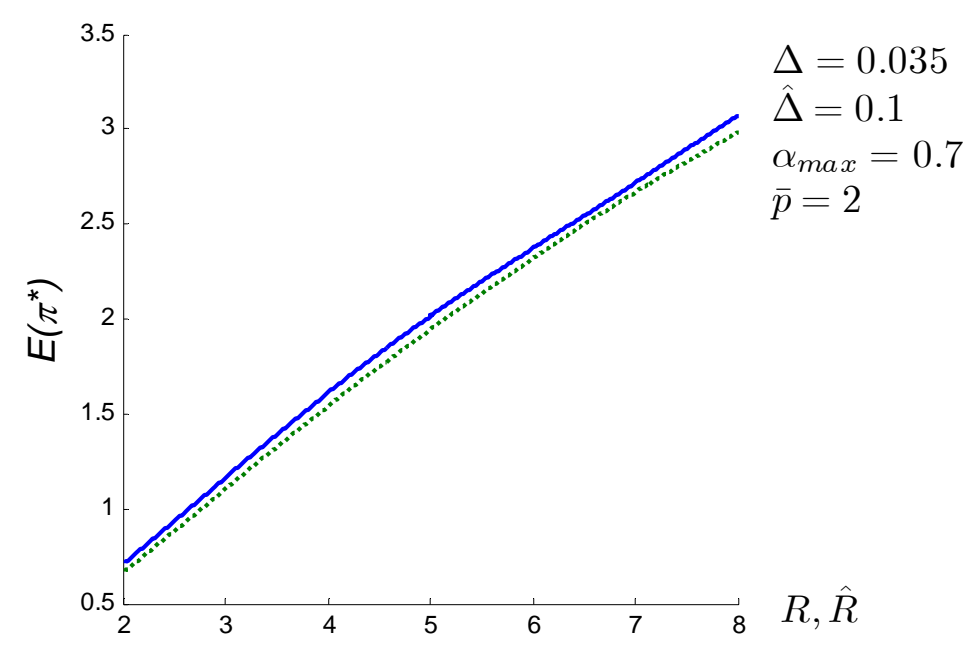

Figure 9c: Effect of $\mathrm{R}$ (Model I) and $\hat{R}$ (Model II)

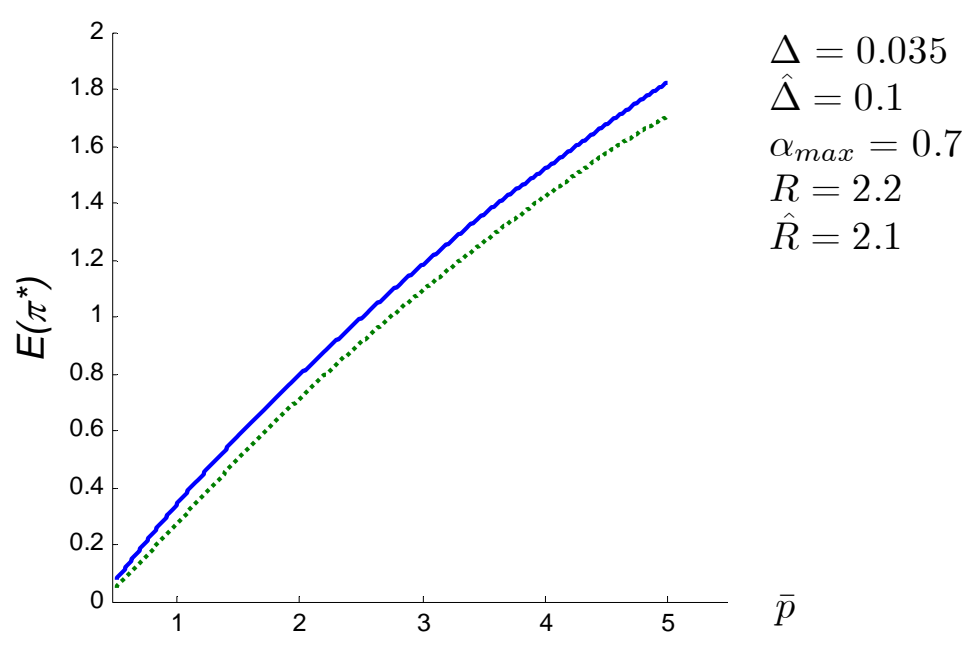

Fig ure 9d: Effect of $\bar{p}$ 